\title{
Augmentation of Macular Pigment Following Supplementation with all Three Macular Carotenoids: an Exploratory Study
}

\author{
Eithne Connolly \\ Waterford Institute of Technology \\ Stephen Beatty \\ Waterford Institute of Technology \\ David Thurnham \\ Technological University Dublin
}

See next page for additional authors

Follow this and additional works at: https://arrow.tudublin.ie/otpomart

Part of the Optometry Commons

\section{Recommended Citation}

Connolly, E., Beatty, S., Thurnham, D., Loughman, J., Howard, A., Stack, J., Nolan, J.: Augmentation of Macular Pigment Following Supplementation with All Three Macular Carotenoids: An Exploratory Study. Current Eye Research, Vol. 35, No. 4, pp. 335-351. April 2010. doi:10.3109/02713680903521951

This Article is brought to you for free and open access by ARROW@TU Dublin. It has been accepted for inclusion in Articles by an authorized administrator of ARROW@TU

Dublin. For more information, please contact

arrow.admin@tudublin.ie, aisling.coyne@tudublin.ie, gerard.connolly@tudublin.ie.

Funder: Howard Foundation, Cambridge, United Kingdom

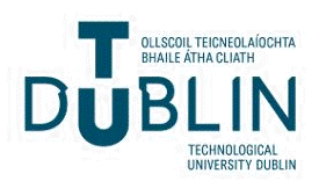




\section{Authors}

Eithne Connolly, Stephen Beatty, David Thurnham, James Loughman, Alan Howard, Jim Stack, and John Nolan

This article is available at ARROW@TU Dublin: https://arrow.tudublin.ie/otpomart/13 


\section{AUTHOR'S QUERY SHEET}

Author(s): Eithne E. Connolly et al.

Article title:

Article no: NCER 452659

\section{Dear Author}

The following queries have arisen during the editing of your manuscript and are identified on the proofs. Unless advised otherwise, please submit all corrections using the CATS online correction form.

AQ1. Please fill in correct page number.

AQ2. Please provide the manufacturers and their locations for SPSS version 17 and SigmaPlot version 8.0 software.

AQ3. Please provide a declaration of interest statement. All articles in Informa Healthcare journals should acknowledge any support/funding received by the authors to carry out the study, or any other commercial relationships relevant to the article's subject matter. If no funding has been received, a statement explicitly declaring no conflict of interest is required.

AQ4. Please provide the volume number and page range for this work.

AQ5. Please provide the volume number and page range for this work.

AQ6. Please verify that $\mathrm{HF}\{$ is correct as shown.

AQ7. Currently your figures will appear in black and white for the print edition. If you would like to pay for figures $1 \mathrm{~A}, 1 \mathrm{~B}$, and 2 to print in color, please indicate so that we may request a cost estimate. 


\title{
Augmentation of Macular Pigment Following Supplementation with All Three Macular Carotenoids: An Exploratory Study
}

Eithne E. Connolly ${ }^{1,2}$, Stephen Beatty ${ }^{1,2}$, David I. Thurnham ${ }^{3}$, James Loughman, Alan N. Howard ${ }^{5,6}$, Jim Stack ${ }^{2}$, and John M. Nolan ${ }^{1,2}$

${ }^{1}$ Macular Pigment Research Group, Department of Chemical and Life Sciences, Waterford Institute of Technology, Waterford, Ireland

${ }^{2}$ Institute of Vision Research, Whitfield Clinic, Waterford, Ireland

${ }^{3}$ Northern Ireland Center for Food and Health (NICHE), University of Ulster, Coleraine, UK

${ }^{4}$ Department of Optometry, School of Physics, Dublin Institute of Technology, Dublin, Ireland

${ }^{5}$ Downing College, University of Cambridge, Cambridge, UK

${ }^{6}$ Howard Foundation, Cambridge, UK

Purpose: At the macula, the carotenoids meso-zeaxanthin (MZ), lutein (L), and zeaxanthin (Z) are collectively referred to as macular pigment (MP). This study was designed to measure serum and macular responses to a macular carotenoid formulation.

Materials and Methods: Ten subjects were recruited into this study (five normal and five with early age-related macular degeneration [AMD]). Subjects were instructed to consume a formulation containing $7.3 \mathrm{mg}$ of $\mathrm{MZ}, 3.7 \mathrm{mg}$ of $\mathrm{L}$, and $0.8 \mathrm{mg}$ of $\mathrm{Z}$ everyday over an eight-week period. The spatial profile of MP optical density (i.e., MPOD at $0.25^{\circ}, 0.5^{\circ}, 1^{\circ}$, and $1.75^{\circ}$ ) was measured using customized heterochromatic flicker photometry, and a blood sample was collected at each study visit in order to analyze serum concentrations of MZ, L, and Z.

Results: There was a significant increase in serum concentrations of $\mathrm{MZ}$ and $\mathrm{L}$ after two weeks of supplementation $(p<0.05)$. Baseline serum carotenoid analysis detected a small peak eluting at the same time as $\mathrm{MZ}$ in all subjects, with a mean $\pm \mathrm{SD}$ of $0.02 \pm 0.01 \mu \mathrm{mol} / \mathrm{L}$. We report significant increases in MPOD at $0.25^{\circ}, 0.5^{\circ}, 1^{\circ}$, and average MPOD across the spatial profile after just two weeks of supplementation ( $p<0.05$, for all). Four subjects (one normal and three AMD) who had an atypical MPOD spatial profile at baseline had the more typical MPOD spatial profile (i.e., highest MPOD at the center) after eight weeks of supplementation.

Conclusion: We report significant increases in serum concentrations of MZ and L following supplementation with MZ, L, and $\mathrm{Z}$ and a significant increase in MPOD, including its spatial profile, after two weeks of supplementation. Also, this study has detected the possible presence of MZ in human serum pre-supplementation and the ability of the study carotenoid formulation to rebuild central MPOD in subjects who have atypical profiles at baseline.
\end{abstract}

KEYWORDS: Age-related macular degeneration; Lutein; Macular pigment; Meso-zeaxanthin; Supplementation 
blindness in developed countries. ${ }^{1,2}$ It is estimated that the number of people suffering from AMD will continue to increase, primarily due to increasing longevity. ${ }^{3,4}$ It is now believed that both oxidative stress and cumulative exposure to short-wavelength (blue) light are involved in the aetiopathogenesis of AMD. ${ }^{5-7}$

The center of the retina has a distinct yellow color attributable to the presence of a pigment known as macular pigment (MP), and this coloration contributed to the original eponymous description of this retinal region as the macula lutea (or yellow spot). ${ }^{8,9} \mathrm{MP}$ comprises three dietary carotenoids meso-zeaxanthin $(\mathrm{MZ})$, lutein $(\mathrm{L})$, and zeaxanthin $(\mathrm{Z}){ }^{8-10}$ There is now a biologically plausible rationale, supported by a growing body of evidence, in support of the view that MP protects against AMD.7 For example, MP has been shown to significantly reduce the amount of blue light incident on the macula. ${ }^{11-14}$ Furthermore, the antioxidant properties of $\mathrm{MP}^{\prime} \mathrm{s}$ constituent carotenoids within the retina and elsewhere have been demonstrated in vitro. ${ }^{15,16}$

$\mathrm{L}$ and $\mathrm{Z}$ are found in a typical western diet, in fruit and vegetables (e.g., spinach, corn, orange peppers, red grapes); ${ }^{17}$ whereas, $\mathrm{MZ}$ is believed to be generated at the macula following a biochemical transformation of L. ${ }^{18,19} \mathrm{MZ}$ has also been identified in some less commonly consumed foods including fish (e.g., salmon and trout), shrimp, and turtle fat ${ }^{20}$; however, to date and in the absence of supplementation with this carotenoid, MZ has not been detected or reported in human serum. From a scientific perspective, we were interested to investigate how individuals respond to an MZ-based supplement (even in combination with the other macular carotenoids) as it has been reported that there is an association between AMD and MP profile $^{21}$ and given that research has shown that $\mathrm{MZ}$ is generated in the retina following $\mathrm{L}$ conversion. It is possible that individuals lacking centrally located $\mathrm{MP}$ require $\mathrm{MZ}$ to be provided in supplement form, as such individuals could (perhaps) lack the capacity to convert $\mathrm{L}$ to $\mathrm{MZ}$ within the retina.

There are several published studies reporting on supplemental L and/or Z, and the impact of such supplementation on MP levels and/or serum concentrations of these carotenoids (Table 1). In 1997, Hammond et al. showed that a diet modified to result in increased consumption of $\mathrm{L}$ and $\mathrm{Z}$, for as little as four weeks, could augment MP, with this effect being maintained for several months following resumption of a normal, unmodified diet. ${ }^{22}$ Of note, two of the 11 subjects involved in that study did not show a significant rise in MP optical density (MPOD), despite a significant increase in serum L concentrations. These subjects were termed "retinal non-responders", and it has been hypothesized that this phenomenon may be due to a compromised ability to capture and/or stabilize the macular carotenoids in these individuals. ${ }^{7}$ Landrum et al. investigated the effect of L supplementation $(30 \mathrm{mg}$ per day) in two individuals over a 140-day period. ${ }^{23}$ They found an increase in serum L concentrations in both individuals, coupled with a parallel increase in MPOD. A more recent investigation reporting on a commercially available L-based supplement with respect to macular and serum response in patients who displayed features of AMD was performed by Trieschmann et al. in 2007. ${ }^{24}$ In that study, the authors concluded that supplementation with $12 \mathrm{mg}$ of $\mathrm{L}$ and $1 \mathrm{mg}$ of $\mathrm{Z}$, combined with co-antioxidants, resulted in a significant increase in MPOD at $0.5^{\circ}$ eccentricity and in the majority of subjects (average increase $\sim 0.1$ optical density units [ODU]).

Of note, there has only been one study to date which investigated the effects of supplemental MZ on MPOD levels in human subjects. ${ }^{25}$ That study, which included 10 subjects, showed that a soya bean oilbased supplement containing $14.9 \mathrm{mg}$ of $\mathrm{MZ}, 5.5 \mathrm{mg}$ of $\mathrm{L}$, and $1.4 \mathrm{mg}$ of $Z$ resulted in an average increase of $\sim 0.07 \mathrm{MPOD}$ at $0.75^{\circ}$ of eccentricity over a 120 day period. ${ }^{25}$ However, limitations of the study performed by Bone et al. include: MPOD was measured at only one point of retinal eccentricity $\left(\sim 0.75^{\circ}\right)$ and would therefore not have been able to detect changes in MPOD, if any, occurring at other retinal eccentricities (e.g., $0.25^{\circ}, 0.5^{\circ}, 1^{\circ}, 1.75^{\circ}$ ), including the more central eccentricities of $0.25^{\circ}$ and $0.5^{\circ}$; no controls were included in the study; small sample size $(n=10)$; and serum concentrations of $\mathrm{MZ}$ was only measured for two subjects.

Our study, the Meso-zeaxanthin Ocular Supplementation Trial (MOST), was designed to evaluate MPOD response, including its spatial profile (i.e., $0.25^{\circ}, 0.5^{\circ}$, $1^{\circ}$, and $\left.1.75^{\circ}\right)$, and serum carotenoid response, in 10 subjects (five normal and five AMD), following consumption of a dietary food supplement containing all three macular carotenoids: $\mathrm{MZ}, \mathrm{L}$, and $\mathrm{Z}$, in which MZ was the predominant carotenoid. The limitations of this pilot investigation are as follows: no controls were included into the study; small sample size $(n=10)$; however, the entire spatial profile of MPOD was assessed (see above) and serum concentrations of MZ were analyzed for all 10 subjects.

\section{METHODS}

\section{Subjects}

This was a non-randomized and open labeled study. All subjects signed an informed consent document 
TABLE 1 Studies reporting on macular pigment optical density response to supplementation with the macular carotenoids

TABLE 1 Studies reporting on macular pigment optical density response to supplementation with the macular carc

Principal author Year Journal Tech No. Age (mg/day) (mg/day) (mg/day) (weeks) eccentricity increase PF Significance

Normal subjects-dietary modification

Hammond et al. 1997 IOVS HFP 10 30-65

Hammond et al. 1997 IOVS

Hammond et al. 1997 IOVS

HFP 2 30-65

11.2

HFP 1 30-65

0.4

Johnson et al.

2000 AJCN

HFP 7 33-54

10.8

NORMAL subjects-supplement modification
Landrum et al. 1997 EER HFP 2 42-51 30

Berendschot et al. 2000 IOVS SLO $8 \quad 18-50 \quad 10$

Berendschot et al. 2000 IOVS

Aleman et al. 2001 IOVS

Aleman et al. 2001 IOVS

Aleman et al.

2001 IOVS

Aleman et al.

2001 IOVS

Bone et al.

2003 JN

Bone et al.

$2003 \mathrm{JN}$

Bone et al.

$2003 \mathrm{JN}$

Bone et al.

$2003 \mathrm{JN}$

Bone et al.

2003 JN

Koh et al.

2004 EER

Bernstein et al. 2004 ABB

Bone et al.

$2007 \mathrm{NM}$

Wenzel et al.

2007 OPO

Wenzel et al.

2007 OPO

Wenzel et al.

2007 OPO

2007 OPO

2007 ABB

Schalch et al.

2007 ABB

2008 AJCN

Johnson et al. 2008 AJCN

Stringham et al. 2008 OVS

Stringham et al. 2008 OVS

Stringham et al. 2008 OVS

Stringham et al. 2008 OVS

SA $8 \quad 18-50 \quad 10$

HFP $8 \quad 11-59 \quad 20$

HFP $8 \quad 11-59 \quad 20$

HFP $8 \quad 11-59 \quad 20$

HFP $8 \quad 11-59 \quad 20$

HFP 2 19-59 30

HFP $153 \quad 0$

HFP $21 \quad 19-59 \quad 2.4$

HFP 12 19-60 20

HFP 2 26-27 5

HFP $6 \quad 64-81 \quad 20$

HFP $8<61 \quad 20$

RRS $8<61 \quad 20$

HFP $10 \quad 21-58 \quad 5.5$

HFP $3 \quad 24-52 \quad 30$

HFP $3 \quad 24-52 \quad 30$

HFP $3 \quad 24-52 \quad 30$

HFP $3 \quad 24-52 \quad 30$

$\begin{array}{llll}\text { HFP } & 23 & 18-45 & 10.7\end{array}$

HFP $23 \quad 18-45 \quad 0$

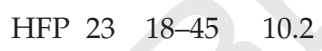

HFP $11 \quad 60-80 \quad 12$

$\begin{array}{lll}\text { HFP } & 11 \quad 60-80 \quad 12\end{array}$

HFP $40 \quad 17-41 \quad 10$

HFP $40 \quad 17-41 \quad 10$

HFP $40 \quad 17-41 \quad 10$

HFP $40 \quad 17-41 \quad 10$

HFP $40 \quad 17-41 \quad 10$

Stringham et al. 2008 OVS
Bernstein et al. 2004 ABB

2007 ABB

0
0
0
0

15
15
15
15

0.6

0.3

0.3

0.57

15

15

15

15

0
0
0
0
0
0
0
1.5
30
0

AMD subjects

\section{L}

Principal author Year Journal Tech No. Age (mg/day) (mg/day) (mg/day) (weeks) eccentricity increase PF Significance

\begin{tabular}{lrlllllllllll}
\hline Koh et al. & 2004 & EER & HFP 7 & $64-81$ & 20 & 0 & 0 & 20 & $1^{\circ}$ & 0.07 & $6^{\circ}$ & $\mathrm{p}>0.05$ \\
Trieschmann et al & 2007 & EER & AF 108 & $51-87$ & 12 & 1 & 0 & 24 & $1^{\circ}$ & 0.1 & $6^{\circ}$ & $\mathrm{p}<0.0008$ \\
Richer et al. & 2007 & OPT & HFP 76 & - & 10 & 0 & 0 & 52 & $1^{\circ}$ & 0.25 & $7^{\circ}$ & $\mathrm{p}<0.05$ \\
\hline
\end{tabular}

$\mathrm{MPOD}=$ macular pigment optical density; $\mathrm{L}=$ Lutein (mg/day); $\mathrm{Z}=$ Zeaxanthin (mg/day); MZ=Meso-zeaxanthin (mg/day);

Tech = technique used to measure MPOD; No. = Number of subjects participating in study; Age=Age range of subjects in study;

$\mathrm{PF}=$ Parafovea stimulus; AJCN = American Journal of Clinical Nutrition; IOVS = Investigative Ophthalmology and Visual Science;

$\mathrm{ABB}=$ Archives of Biochemistry and Biophysics; $\mathrm{OPO}=$ Ophthalmic and Physiological Optics; EER = Experimental Eye Research;

$\mathrm{NM}=$ Nutrition and Metabolism; OPT = Optometry; JN = Journal of Nutrition; OVS=Optometry and Vision Science; RC=Raman counts; $\mathrm{ODU}=$ Optical density units; $\mathrm{HFP}=$ Heterochromatic flicker photometry; $\mathrm{AF}=$ Autofluorescence; $\mathrm{SLO}=\mathrm{Scanning} \mathrm{Laser}$ ophthalmoscope; $\mathrm{SA}=$ Spectral Analysis; $\mathrm{AMD}=$ Age related Macular Degeneration; RRS=Resonance Raman Spectroscopy; - = data unavailable. 
and the experimental measures conformed to the Declaration of Helsinki. The study was reviewed and approved by the Research Ethics Committee, South East Region, Waterford Regional Hospital, Waterford, Ireland.

This study consisted of two groups; Group $1(n=5)$, inclusion criteria: male or female between the age of 18 and 60 years; no presence of ocular pathology; visual acuity of at least 6/18 in the study eye. Exclusion criteria: individuals outside age range 18-60 years; pregnancy; presence of ocular pathology; currently taking supplements containing MZ, L, or Z. Group 2 $(n=5)$, inclusion criteria: male or female; early AMD (defined using the International Classification and Grading System for Age-Related Maculopathy and Age-Related Macular Degeneration) ${ }^{26}$ in at least one eye with best corrected visual acuity of at least 6/18 in that eye, hereafter known as the study eye for this group. Exclusion criteria: currently taking supplements containing $\mathrm{MZ}, \mathrm{L}$, or Z; presence of ocular pathology other than AMD.

The mixture of carotenoids was manufactured by Industrial Organica SA, Monterrey, Mexico by isomerizing L obtained from marigold extracts. A proportion of the L was converted into $\mathrm{MZ}$, and the small quantity of $Z$ in the extract remained unchanged. The resulting composition was microencapsulated after diluting with rice starch. Each capsule contained $7.3 \mathrm{mg} \mathrm{MZ,} \mathrm{3.7} \mathrm{mg}$ $\mathrm{L}$, and $0.8 \mathrm{mg} \mathrm{Z}$. We used a carotenoid formulation containing high amounts of $\mathrm{MZ}$, as this carotenoid is now commercially available and reports on its response in human subjects, to date, are limited. In addition, we now present a scientific rationale for supplementation with this carotenoid in our Introduction (see page 000, paragraph 1).

All subjects (in both groups) were instructed to take one capsule per day with a meal for 60 days. MPOD, including its spatial profile (i.e., $0.25^{\circ}, 0.5^{\circ}, 1^{\circ}, 1.75^{\circ}$ ), was measured at baseline and at two week intervals (V1: Baseline; V2: 2 weeks; V3: 4 weeks; V4: 6 weeks; V5: 8 weeks) over the 60 days (see Method below). In Group 1, the eye with better visual acuity was chosen as the study eye; however, where both eyes had the same corrected acuity, the right eye was chosen as the study eye.

A blood sample was collected at each study visit for serum carotenoid analysis of MZ, L, and Z (see Methods below). Demographic, lifestyle, and vision information was also collected from each subject as follows: name, contact information, age, sex, BMI, smoking habits, lifestyle, medication, and vision history. Best corrected visual acuity (BCVA) was measured using $\log$ MAR.

\section{Serum Total $L$ and Total $Z$ analysis-Assay I}

Blood samples $(6-8 \mathrm{~mL})$ were collected from all patients on the same day as MPOD assessment. Serum was separated from blood by centrifugation (DESAGA Starstedt-Gruppe, GC12) 2500 RPM for $10 \mathrm{~min}$, and then aliquoted into two amber light-sensitive microcentrifuge tubes and stored at minus $70^{\circ} \mathrm{C}$ until time of analysis. A $400 \mu \mathrm{L}$ aliquot of serum was pipetted into an amber light-sensitive microcentrifuge tube $(1.5 \mathrm{~mL}$ total capacity). Ethanol $(300 \mu \mathrm{L})$ containing $0.25 \mathrm{~g} / \mathrm{L}$ butylated hydroxytoluene (BHT) and $200 \mu \mathrm{L}$ internal standard ( $\alpha$-tocopherol acetate $[0.25 \mathrm{~g} / \mathrm{L}])$ were added to each tube. Heptane $(500 \mu \mathrm{L})$ was then added and samples were vortexed vigorously for $2 \mathrm{~min}$ followed by centrifugation at $2000 \mathrm{rpm}$ for $5 \mathrm{~min}$ (MSC Micro Centaur, Davison \& Hardy Ltd., Belfast, UK). The resulting heptane layer was retained and transferred to a second labeled amber light-sensitive microcentrifuge tube, and a second heptane extraction was performed. The combined heptane layers were immediately evaporated to dryness under nitrogen. These dried samples were reconstituted in $200 \mu \mathrm{L}$ methanol (containing $0.25 \mathrm{~g} / \mathrm{L}$ $\mathrm{BHT}$ ), and $100 \mu \mathrm{L}$ was injected for high-performance liquid chromatography (HPLC) analysis.

We used an Agilent 1200 series (Agilent Technologies Ltd., Dublin, Ireland) system with photodiode array detection at a wavelength of $450 \mathrm{~nm}$. A $5 \mu \mathrm{m}$ analyti$\mathrm{cal} /$ preparative $4.6 \times 250 \mathrm{~mm} 201 \mathrm{TP}$ speciality reverse phase column (Vydac, Hesperia, California, USA) was used with an in-line guard column. The mobile phase consisted of $97 \%$ methanol and 3\% tetrahydrofuran. The flow rate was $1 \mathrm{~mL} / \mathrm{min}$, and the total run time was $15 \mathrm{~min}$.

DSM Nutritional Products (Basel, Switzerland) provided total L (TL) and total Z (TZ) standards to generate response factors that were used to calculate serum concentrations of TL and TZ. An internal standard, $\alpha$-tocopherol acetate, made up in ethanol $(0.25 \mathrm{mg} / \mathrm{L})$ was used to correct for recovery of extractions for HPLC analysis and assist quantification. All chromatograms were integrated manually by drawing a baseline and dropping perpendicular lines to quantify the peaks of interest (Figure 1A). All carotenoid peaks were integrated and quantified using Agilent ChemStation software. Figure 1A shows a typical chromatogram generated from the above described assay.

\section{Serum MZ Analysis-Assay 2}

Assay 1 outlined above resulted in separation of TL and TZ. The eluent that corresponded to the peak of 


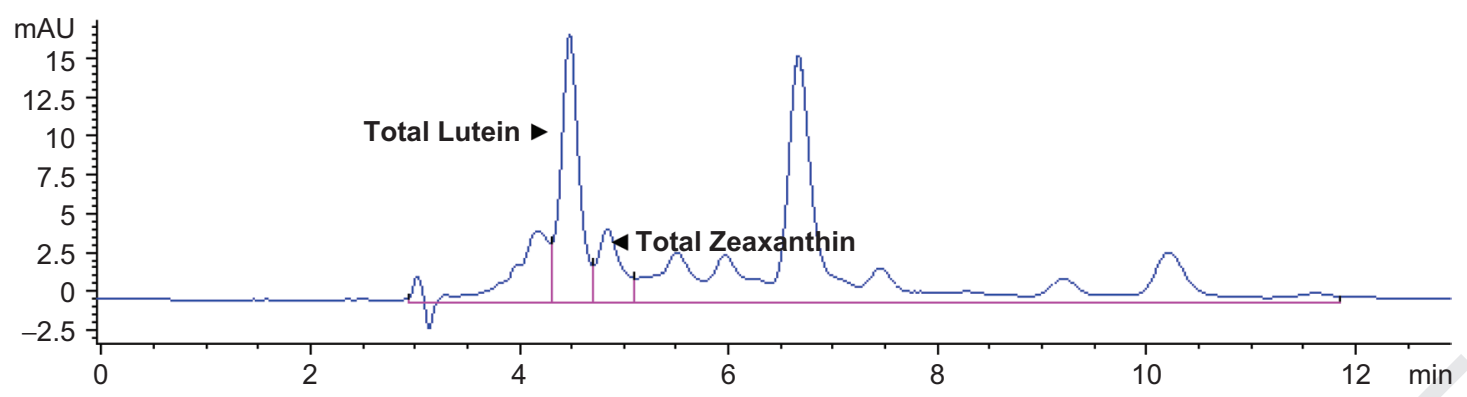

FIGURE 1A Chromatogram showing lutein and zeaxanthin peaks obtained from assay 1 using high performance liquid chromatography as follows. Column: 5 micron analytical/preparative $4.6 \times 250 \mathrm{~mm}$ 201TP speciality reverse phase; detector: photo diode array and UV; wavelength: $450 \mathrm{~nm}$; mobile phase: $97 \%$ methanol and 3\% tetrahydrofuran; run time: $15 \mathrm{~min}$; elution: isocratic. All peaks were integrated manually using Chemstation software.

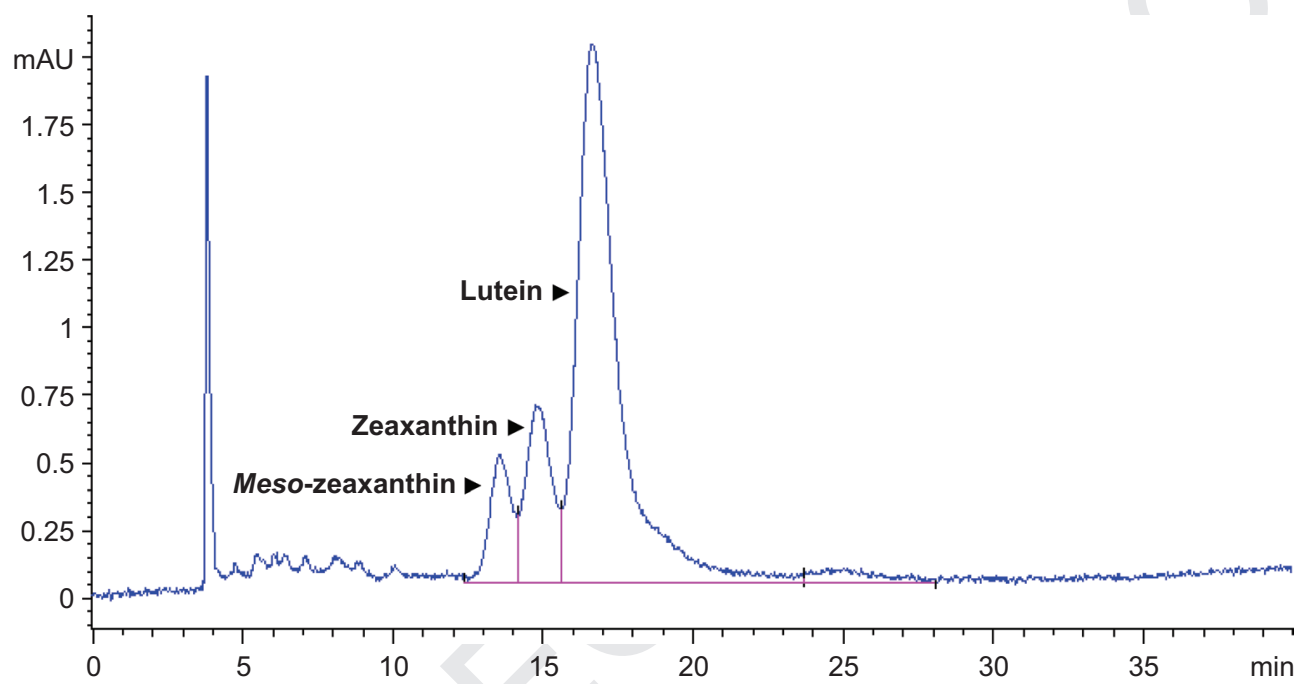

FIGURE 1B Chromatogram showing zeaxanthin isomer peaks (1 and 2) obtained from assay 2. Peak 3 is a lutein peak collected into fraction 1 . The eluate also contained some TL, as TL and $\mathrm{TZ}$ were not baseline separated in the first fractionation; therefore, it is not possible to collect just TZ from the waste line. The method used is as follows. Column: Chiralpak ${ }^{\mathrm{TM}} \mathrm{AD}$ column $(250 \times 4.6 \mathrm{~mm})$; detector: diode array; wavelength: $450 \mathrm{~nm}$; mobile phase: isopropanol and n-hexane; run time: $30 \mathrm{~min}$; elution: gradient, starting at $90 \%$ n-hexane and $10 \%$ isopropanol, increasing to $95 \%$ n-hexane. All peaks were integrated manually using Chemstation software.

$\mathrm{TZ}$ from assay 1 was collected from the waste line (fraction 1) and evaporated to dryness under nitrogen. Fraction 1 also contained some TL, as TL and TZ eluted close together, which made it difficult to collect just TZ from the waste line. All dried down samples were then reconstituted in $50 \mu \mathrm{L}$ of n-hexaneisopropanol (90:10) and $40 \mu \mathrm{L}$ was injected onto the $10 \mu \mathrm{m}$ Chiralpak ${ }^{\mathrm{TM}}$ AD column $(250 \times 4.6 \mathrm{~mm}$; Chiral Technologies Europe, France) protected by a Chiralpak $^{\mathrm{TM}}$ guard column and a $2 \mu \mathrm{m}$ filter. In order to achieve separation of the $\mathrm{Z}$ isomers ( $\mathrm{Z}$ and $\mathrm{MZ})$, a flow rate of $0.8 \mathrm{~mL} / \mathrm{min}$ with the following gradient elution: starting at $90 \%$ n-hexane and 10\% isopropanol, and increasing to $95 \%$ n-hexane over $30 \mathrm{~min}$ was used..$^{27}$ Integration was manually carried out on the resulting chromatogram from assay 2 by drawing a baseline between $\sim 13$ and $\sim 30$ min and then dropping a perpendicular line to quantify the proportions of $Z$ and MZ from their peak areas. The proportions of the $\mathrm{Z}$ isomers were assumed to be the same as in the TZ fraction from the column of assay 1 , which enabled calculation of the individual amounts of $\mathrm{Z}$ and $\mathrm{MZ}$ in the $\mathrm{TZ}$ fraction. A sample chromatogram showing the $\mathrm{MZ}$ and $\mathrm{Z}$ peaks is presented in Figure 1B.

\section{Macular Pigment Optical Density}

MPOD was measured using the Macular Metrics Densitometer ${ }^{\mathrm{TM}}$, developed by Professor B. R. Wooten of Brown University, Providence, Rhode Island, USA, using heterochromatic flicker photometry (HFP). The 
device was modified from the one described original$1 y{ }^{28}$ Two different techniques for measuring MPOD using this device were employed for normal subjects (Group 1-“method of adjustment") and AMD subjects (Group 2-"bracketing method"), and are described below. We used the bracketing procedure for the AMD subjects as we find this procedure more suitable for older subjects (see below). All subjects were trained how to perform the HFP task at their first study visit. MPOD data was not recorded until subjects demonstrated a high level of understanding of the task. Reliability and reproducibility of MPOD measurements obtained using the Macular Metrics Densitometer ${ }^{\mathrm{TM}}$ have previously been reported. ${ }^{29,30}$

\section{Background Common to Both Techniques}

In order to measure MPOD, the subject views a stimulus that alternates between a wavelength band absorbed by MP and one that is not. The radiance of the wavelength band absorbed by MP is adjusted in order to minimize the subjects' percept of flicker. The range of alternation rates where flicker is not perceived is called the null zone. Primarily because of inter-individual differences in temporal (e.g., flicker) sensitivity, it is optimal to customize the HFP task for each subject by selecting the alternation rate to achieve a null zone and a precise setting. This has been termed as customized HFP (cHFP). ${ }^{31}$

The first methodological consideration when using cHFP is selecting the appropriate flicker rate. Selecting the best flicker rate for each subject enables one to accommodate the variation in flicker sensitivity due to factors such as age and disease. ${ }^{32,33}$ If differences among subjects in flicker sensitivity are not accounted for (i.e., a fixed flicker frequency is used), then a subject with low flicker sensitivity (i.e., low critical flicker fusion frequency-CFF) will most likely experience a large null flicker zone. Alternatively, a subject with a high CFF may not be able to eliminate flicker from the test target, which would make the task difficult to complete.

Predicted optimal HFP flicker frequencies were estimated in order to facilitate good subject performance and reduce measurement error. To achieve this, we used an age-guided algorithm to estimate optimal HFP flicker frequencies for all the measurements performed (i.e., the measurement locus at $0.25^{\circ}, 0.5^{\circ}, 1^{\circ}, 1.75^{\circ}$, and reference locus at $7^{\circ}$ ). This algorithm was informed by many years' experience with the Densitometer ${ }^{\mathrm{TM}}$ at several different laboratories (see Table 2).

The second methodological consideration involves a test stimulus configuration in which the radiances of the two alternating components are inverse-yoked. In other words, when the blue component is adjusted to be more intense, the luminance of the green compo- nent is commensurately decreased, and vice versa. This procedure keeps the brightness of the test stimulus relatively constant. This approach is regarded as an improvement because some subjects find changes in brightness distracting when they perform the task.

In this study we measured the spatial profile of MP at four different retinal eccentricities: $0.25^{\circ}, 0.5^{\circ}$, $1^{\circ}$, and $1.75^{\circ}$ with a reference point at $7^{\circ}$. The targets and fixation points used for each retinal eccentricity measured were as follows: the $0.25^{\circ}$ and $0.5^{\circ}$ eccentricities were measured using a $0.5^{\circ}$ and $1^{\circ}$ diameter disc with a $5 \mathrm{~min}$ black fixation point at the center; the $1^{\circ}$ and $1.75^{\circ}$ eccentricities were measured using a $20 \mathrm{~min}$ wide annuli with mean radii corresponding to those eccentricities were used with a centrally fixated $5 \mathrm{~min}$ black fixation point. The $7^{\circ}$ reference measurement was a $2^{\circ}$ diameter disc located $7^{\circ}$ nasally with reference to a $5 \mathrm{~min}$ red fixation point (Figure 2). For the purpose of this study, we assume that flicker perception is dominated by the edges of the disc-shaped stimuli used in each instrument, although other research has suggested that this may not be the case. ${ }^{34}$

\section{Group I-Method of Adjustment}

Prior to MP measurement, subjects were shown a video that described the task in hand, with instructions. The first measurement of MP was carried out at $0.5^{\circ}$ retinal eccentricity. The subject was instructed to place his/her study eye at the viewing eyepiece and the examiner ensured that the tilt of the main unit allowed comfortable viewing for the subject. The appropriate flicker frequency was set for the subject's age. The examiner set the radiance button all the way to the left (i.e., lowest blue light intensity) or right (i.e., highest blue light intensity). The subject then pushed the first of the radiance control buttons (on the left

TABLE 2 Predicted optimal flicker frequency for densitometer ${ }^{\mathrm{TM}}$ targets

\begin{tabular}{|c|c|c|c|}
\hline Age & OFF $0.25^{\circ}$ & OFF $0.5^{\circ}, 1^{\circ}, 1.75^{\circ}$ & OFF $7^{\circ}$ \\
\hline $18-20$ & 18 & 19 & 13 \\
\hline $21-30$ & 18 & 19 & 12 \\
\hline $31-40$ & 17 & 18 & 11 \\
\hline $41-50$ & 15 & 16 & 10 \\
\hline $51-60$ & 13 & 14 & 9 \\
\hline $61-70$ & 12 & 13 & 8 \\
\hline $71-80$ & 11 & 12 & 7 \\
\hline $81+$ & 10 & 11 & 6 \\
\hline \multicolumn{4}{|c|}{$\begin{array}{l}\mathrm{OFF}=\text { optimal flicker frequency; } 0.25^{\circ}=\mathrm{MPOD} \text { measured at } \\
0.25^{\circ} \text { retinal eccentricity; } 0.5^{\circ}=\mathrm{MPOD} \text { measured at } 0.5^{\circ} \text { retinal } \\
\text { eccentricity; } 1^{\circ}=\mathrm{MPOD} \text { measured at } 1^{\circ} \text { retinal eccentricity; } \\
1.75^{\circ} \mathrm{MPOD}=\mathrm{MPOD} \text { measured at } 1.75^{\circ} \text { retinal eccentricity; } \\
7^{\circ}=\mathrm{MPOD} \text { measured at } 7^{\circ} \text { retinal eccentricity. This algorithm } \\
\text { developed by Nolan and Stringham was used to estimate opti- } \\
\text { mal HF\{ flicker frequencies for each retinal locus, including the } \\
\text { reference locus. }\end{array}$} \\
\hline
\end{tabular}



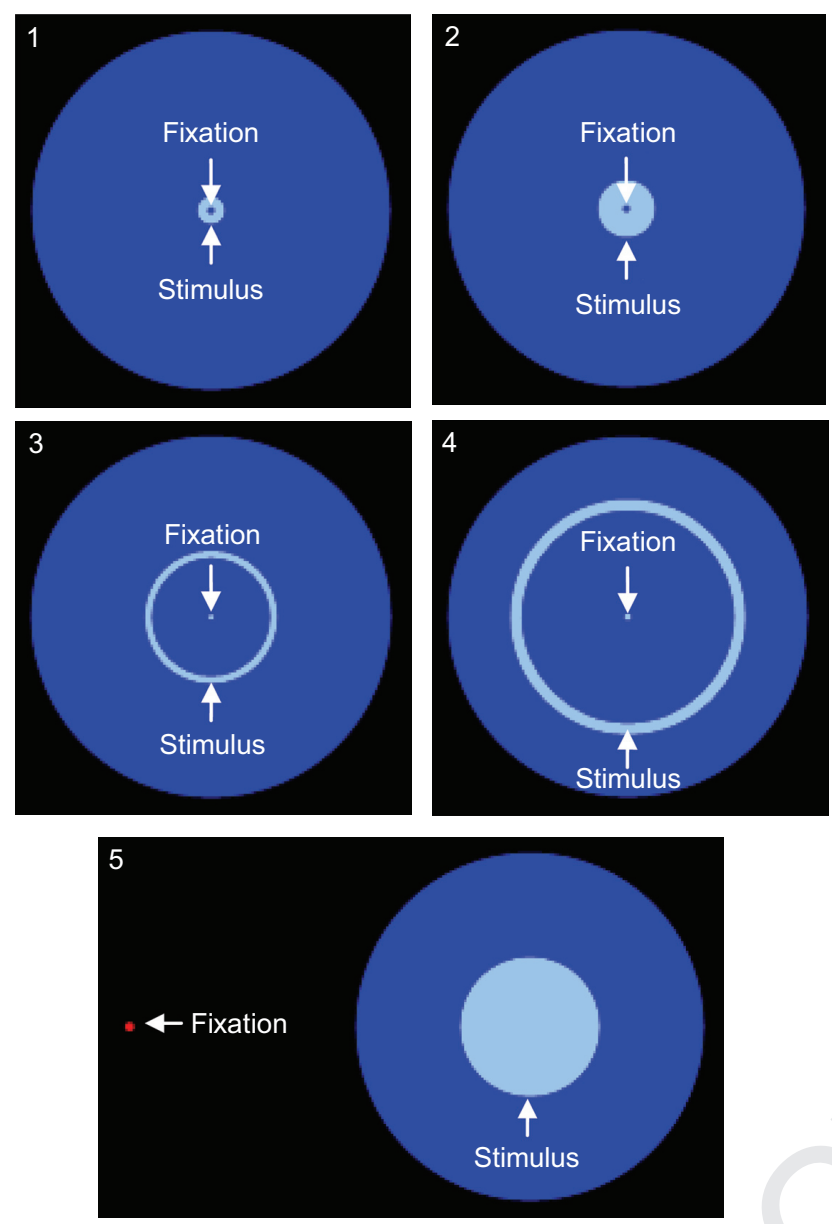

FIGURE 2 MPOD = macular pigment optical density; Fixation $=$ fixation point for stimulus; Stimulus $=$ stimulus viewed by subject; $1=$ target used to measure MPOD at $0.25^{\circ}$ retinal eccentricity (stimulus diameter $=0.5^{\circ}$ disc); 2 = target used to measure MPOD at $0.5^{\circ}$ retinal eccentricity (stimulus diameter $=1^{\circ}$ disc); $3=$ target used to measure MPOD at $1^{\circ}$ retinal eccentricity (stimulus diameter $=20 \mathrm{~min}$ annulus with mean radius corresponding to $1^{\circ}$ ); 4 = target used to measure MPOD at $1.75^{\circ}$ retinal eccentricity (stimulus diameter $=20 \mathrm{~min}$ annulus with mean radius corresponding to $1.75^{\circ}$ ); $5=$ target used to measure MPOD at $7^{\circ}$ retinal eccentricity (stimulus diameter $=2^{\circ}$ disc with reference to a red fixation point at $7^{\circ}$ ).

of the control pad) that electronically, smoothly and continuously altered the blue/green ratio until the beginning of the null flicker zone was reached. The subject continued to hold down the button until the end of the null flicker zone was reached. Once the null flicker zone had been defined, the subject used the second radiance control button (on the right) to go back through the no flicker zone. The subject then used both radiance control buttons to go back and forth through the null flicker zone until the center of the zone (i.e., their null flicker point) was identified, and the radiance value at this point was then recorded by the examiner. After each measurement, the examiner offset the radiance button to a random position and the subject repeated the test as above. This procedure was repeated on four more occasions and the radiance values were recorded in the MPOD log form. The same procedure was repeated for measurements (see above) at the following retinal eccentricities $0.25^{\circ}, 1^{\circ}, 1.75^{\circ}, 7^{\circ}$ (Figure 2). MPOD was then calculated using the log ratio of the measurement radiance values with respect to the reference radiance values obtained for each subject at $7^{\circ}$, using a method of adjustment MPOD calculator provided by Macular Metrics (Providence, Rhode Island, USA).

Of note, if the subject reported that there was no null flicker zone, the examiner increased the flicker frequency by two $\mathrm{Hz}$. If the subject reported a very wide null zone then the flicker frequency was reduced by two Hz. These steps were repeated if necessary.

\section{Bracketing Method-Group 2}

The "bracketing method" developed by members of the Macular Pigment Research Group, Waterford, Ireland (Dr. John M. Nolan, Dr. Edward Loane) and Professor B.R. Wooten of Brown University, US (Densitometer ${ }^{\mathrm{TM}}$ inventor), allowed us to obtain quick, but accurate and customized, MPOD values for Group 2 and is described below.

A diagrammatic representation of the initial test stimulus was used to familiarize the subject with the nature of the task (Figure 2). The examiner selected the target required to measure MPOD at $0.5^{\circ}$ eccentricity $\left(1^{\circ}\right.$ stimulus (Figure 2$)$ ). The subject was instructed to place his/her study eye at the viewing eyepiece and the examiner ensured that the tilt of the main unit allowed comfortable viewing for the subject. The appropriate flicker frequency was set for the subject's age. The examiner set the radiance button all the way to the left (i.e., lowest blue light intensity). The examiner then pushed a button that electronically, smoothly and continuously altered the blue/green ratio until the subject reported that there was no flicker. The radiance value obtained was recorded and this same procedure was repeated on four more occasions and recorded in the MPOD log form. The examiner set the radiance button all the way to the right (i.e., highest blue light intensity) and repeated the test four times as above. This completed the first part of the measurement (ten radiance values obtained in total, five approaching from the lowest blue light intensity and five approaching from highest blue light intensity). The same procedure was repeated for measurements (see above) at the following retinal eccentricities $0.25^{\circ}, 1^{\circ}, 1.75^{\circ}, 7^{\circ}$, and MPOD was calculated using the log ratio of the measurement radiance values with respect to the reference radiance values obtained for each subject at $7^{\circ}$, using a bracketing procedure MPOD calculator provided by Macular Metrics (Providence, Rhode Island, USA). 
Previous models of the densitometer (and most other similar devices) control the blue/green energy ratio with a rotary dial. Thus, the subject (if using method of adjustment) or the examiner (if using bracketing) turn the dial until the desired point of null flicker is reached. This works well for most subjects. However, some are prone to adjust the dial much too slowly. Others, on the other hand, make their adjustments too quickly. In the bracketing procedure, there are individual differences in the way different examiners control the dial. The current version of the densitometer avoids these potential sources of variability by substituting the dial with two push buttons: one button when depressed and held down causes the blue/green ratio to increase, whereas the other causes the blue/green ratio to decrease. Unlike a subject or examiner turning a dial, the rate of blue/green change is controlled entirely by the densitometer's electronics and was determined to be optimal (neither too fast or too slow) at $7 \mathrm{sec}$ for a sweep from one extreme to the other of the blue/green ratio. Preliminary studies have shown that this new procedure not only removes the aforementioned variability, but the task is qualitatively easier for the subjects. Although the bracketing method was introduced to aid ease of use, there was one AMD subject (subject 10) who was unable to complete the test, despite several attempts to explain the procedure. Results from this subject were unreliable (i.e., repeated measures or variation within measurement greater than $10 \%$ ) and were therefore excluded from all MPOD analysis and presentation.

\section{Statistical Analysis}

AQ2 The statistical software package SPSS (version 17) was used for analysis and SigmaPlot (version 8.0) was used for graphical presentations. Between group differences (Normal [Group 1] vs. AMD [Group 2] in age, BMI, baseline serum carotenoid concentration and baseline MPOD levels [Table 2]) were investigated using independent samples t-tests. Between group differences in sex were investigated using the standard Chi square test. Pearson correlation coefficient analyzes were conducted to investigate the relationship between bivariables. All quantitative variables investigated exhibited a typical normal distribution. Means \pm SDs are presented in the text and tables. We conducted repeated measures analysis of variance for MPOD, including its spatial profile, and serum concentrations of MZ, TL, $\mathrm{TZ}$, and $\mathrm{Z}$ measured at each of five study visits using a general linear model approach. Differences between two time points, within subjects, were assessed using paired samples $t$-test. We used the 5\% level of significance throughout our analysis.

\section{RESULTS}

The demographic, lifestyle, baseline macular serum carotenoid concentrations, and baseline MPOD data for the entire study group, Normal subjects (Group 1) and AMD subjects (Group 2) are presented in Table 3. As seen from this table, age was the only variable for which a statistically significant between group difference was observed $(p=0.001)$.

\section{Alterations in Serum Macular Carotenoid Concentrations Following Supplementation}

We conducted a repeated measures analysis of variance for serum concentrations of MZ, TL, TZ, and Z quantified at each of the five study visits using a general linear model approach. The results are summarized in Table 4; the $p$ values displayed in the final column of this table were obtained using the Huynh-Feldt correction for sphericity. Use of the more conservative Greenhouse-Gesser correction would have led, in all cases, to the same conclusions regarding statistical significance. It is clear from Table 4 and the mean plots of Figures 3, 4, and 5 that the serum concentrations of MZ, TL, and TZ increase significantly with time; whereas, there was no significant time effect for serum concentrations of Z ( $p=0.909)$ (Table 4, Figure 6). Post hoc analysis (paired samples $t$-tests) revealed that the significant increase from baseline was present after two weeks of supplementation (TL: $p<0.05$; TZ: $p<0.05$, and MZ: $p=0.01)$. The data for each individual subject are presented in Table 5.

\section{Alterations in the Spatial Profile of MPOD Following Macular Carotenoid Supplementation}

We conducted a repeated measures analysis of variance for MPOD (at $0.25^{\circ}, 0.5^{\circ}, 1^{\circ}, 1.75^{\circ}$, and average MPOD for all these eccentricities) measured at each of the five study visits using a general linear model approach. The results are summarized in Table 6; the $p$ values displayed in the final column of this table were obtained using the Huynh-Feldt correction for sphericity. Use of the more conservative GreenhouseGesser correction would have led, in all cases, to the same conclusions regarding statistical significance. It is clear from Table 7 and the mean plots of Figure 7 that MPOD at $0.25^{\circ}, 1^{\circ}$ and average MPOD across the retina all increase significantly with time; whereas, there was no significant time effect for MPOD at $0.5^{\circ}$ and $1.75^{\circ}$ throughout the study period $(p=0.101$ and $p=0.61$ ). Of note, the biggest increase seen in MPOD 
TABLE 3 Baseline characteristics for Group 1 and Group 2

\begin{tabular}{lcccc}
\hline Characteristic & Entire group & Group 1 & Group 2 & $p$-Value \\
\hline Age & $53 \pm 21$ & $35 \pm 9$ & $72 \pm 11$ & $\mathrm{p}=0.001$ \\
Sex $^{\mathrm{a}}$ & $5 \mathrm{M}, 5 \mathrm{~F}$ & $2 \mathrm{M}, 3 \mathrm{~F}$ & $3 \mathrm{M}, 2 \mathrm{~F}$ & $\mathrm{p}=0.527$ \\
$\mathrm{BMI}^{\text {Serum } \mathrm{TL}^{\mathrm{b}}}$ & $27 \pm 4$ & $24.8 \pm 1.8$ & $29.4 \pm 4.3$ & $\mathrm{p}=0.075$ \\
Serum TZ $^{\mathrm{c}}$ & $0.302 \pm 0.103$ & $0.314 \pm 0.086$ & $0.290 \pm 0.126$ & $\mathrm{p}=0.728$ \\
Serum MZ & $0.131 \pm 0.070$ & $0.169 \pm 0.78$ & $0.093 \pm 0.036$ & $\mathrm{p}=0.082$ \\
Serum Z & $0.023 \pm 0.007$ & $0.022 \pm 0.005$ & $0.023 \pm 0.009$ & $\mathrm{p}=0.735$ \\
$0.25^{\circ} \mathrm{MPOD}$ & $0.108 \pm 0.067$ & $0.147 \pm 0.74$ & $0.070 \pm 0.030$ & $\mathrm{p}=0.063$ \\
$0.5^{\circ} \mathrm{MPOD}$ & $0.39 \pm 0.19$ & $0.45 \pm 0.17$ & $0.30 \pm 0.20$ & $\mathrm{p}=0.245$ \\
$1^{\circ} \mathrm{MPOD}$ & $0.38 \pm 0.16$ & $0.44 \pm 0.13$ & $0.30 \pm 0.17$ & $\mathrm{p}=0.205$ \\
$1.75^{\circ} \mathrm{MPOD}$ & $0.26 \pm 0.15$ & $0.30 \pm 0.10$ & $0.23 \pm 0.21$ & $\mathrm{p}=0.519$ \\
Average MPOD & $0.14 \pm 0.10$ & $0.12 \pm 0.08$ & $0.17 \pm 0.14$ & $\mathrm{p}=0.556$ \\
\hline
\end{tabular}

${ }^{\mathrm{a}} \mathrm{M}=$ male, $\mathrm{F}=$ female.

${ }^{b}$ Total lutein $(\mu \mathrm{mol} / \mathrm{L})$.

cTotal zeaxanthin $(\mu \mathrm{mol} / \mathrm{L})$.

${ }^{\mathrm{d}}$ Meso-zeaxanthin $(\mu \mathrm{mol} / \mathrm{L})$.

eZeaxanthin ( $\mu \mathrm{mol} / \mathrm{L})$.

Mean \pm SD; Group 1 = normal subjects; Group 2=AMD subjects (Age-related Macular Degeneration); BMI=body mass index; $\mathrm{MPOD}=$ macular pigment optical density; $0.25^{\circ} \mathrm{MPOD}=\mathrm{MPOD}$ measured at $0.25^{\circ}$ retinal eccentricity; $0.5^{\circ} \mathrm{MPOD}=\mathrm{MPOD}$ measured at $0.5^{\circ}$ retinal eccentricity; $1.0^{\circ} \mathrm{MPOD}=\mathrm{MPOD}$ measured at $1.0^{\circ}$ retinal eccentricity; $1.75^{\circ} \mathrm{MPOD}=\mathrm{MPOD}$ measured at $1.75^{\circ}$ retinal eccentricity; Average $\mathrm{MPOD}=$ average $\mathrm{MPOD}$ of all degrees of retinal eccentricity $\left(0.25^{\circ}, 0.5^{\circ}, 1.0^{\circ}\right.$, and 1.75 degrees of retinal eccentricity).

TABLE 4 Average serum results for all subjects at each study visit

\begin{tabular}{|c|c|c|c|c|c|c|}
\hline & V1 & $\mathrm{V} 2$ & +2 & V4 & V5 & $p$-Value \\
\hline Total lutein & $0.30 \pm 0.1$ & $0.36 \pm 0.12$ & $0.40 \pm 0.14$ & $0.37 \pm 0.12$ & $0.36 \pm 0.12$ & $p=0.002$ \\
\hline Total zeaxanthin & $0.13 \pm 0.07$ & $0.16 \pm 0.06$ & $0.18 \pm 0.07$ & $0.16 \pm 0.05$ & $0.17 \pm 0.06$ & $p=0.003$ \\
\hline Meso-zeaxanthin & $0.02 \pm 0.01$ & $0.06 \pm 0.02$ & $0.07 \pm 0.03$ & $0.06 \pm 0.02$ & $0.06 \pm 0.03$ & $p=0.000$ \\
\hline Zeaxanthin & $0.11 \pm 0.07$ & $0.10 \pm 0.05$ & $0.11 \pm 0.05$ & $0.10 \pm 0.04$ & $0.11 \pm 0.04$ & $p=0.909$ \\
\hline
\end{tabular}

Values represent mean $\pm \mathrm{SD}$ in $\mu \mathrm{mol} / \mathrm{L}$; N = 10; V1 = visit 1, V2 = visit 2, V3 = visit 3, V4 = visit 4, V5=visit 5. The $p$-values represent repeated measures ANOVA for the 5 study visits, with Huynh-Feldt corrections for lack of sphericity.

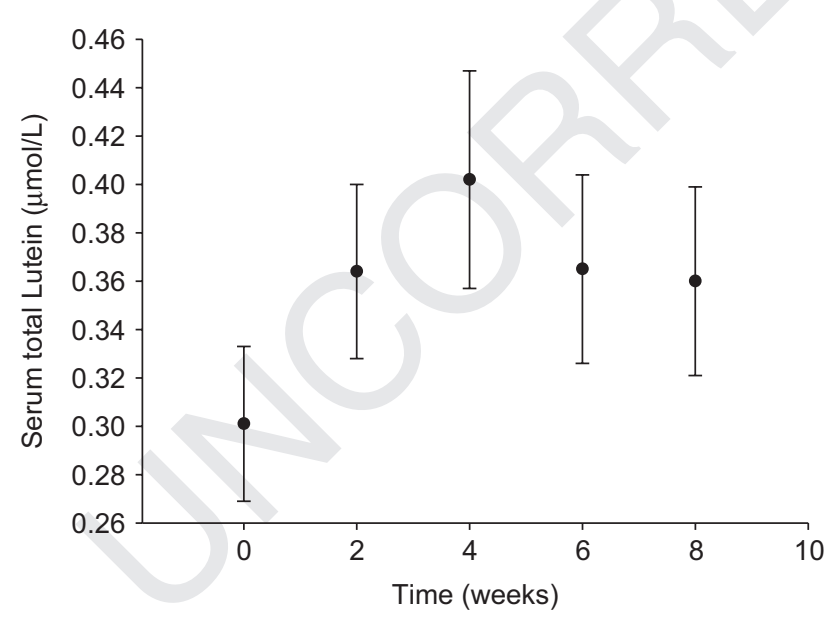

FIGURE 3 Mean ( \pm standard error) serum total lutein concentrations for 10 subjects over the 8-week study period.

was nearest the center (i.e., at eccentricity $0.25^{\circ}$ ) (see Table 6 and Figure 7).

Post hoc analysis (paired samples $t$-tests) revealed that a significant increase from baseline was present

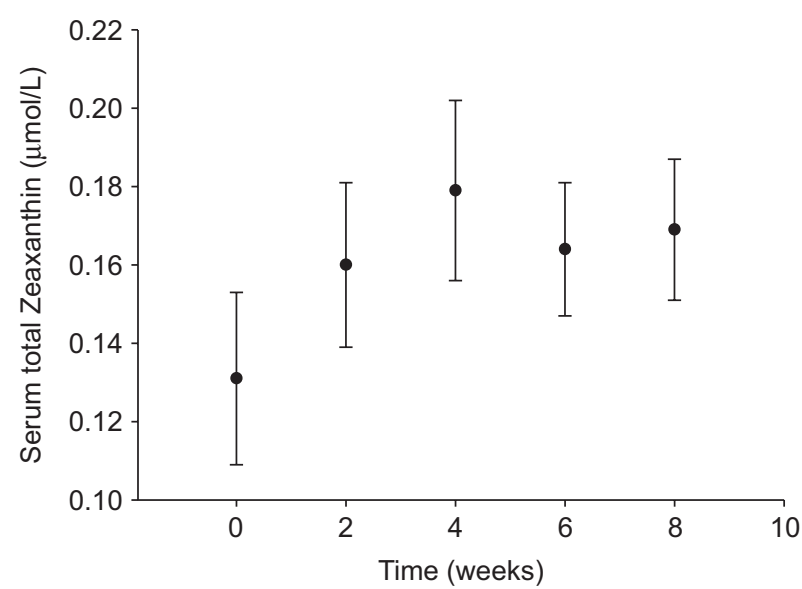

FIGURE 4 Mean ( \pm standard error) serum total zeaxanthin concentrations for 10 subjects over the 8-week study period.

after two weeks of supplementation $(p<0.005$, for all), with the exception of MPOD at $1.75^{\circ}$, which was significantly different from baseline only at V3 $(p=0.004)$. The data for each individual subject is presented in Table 7. 


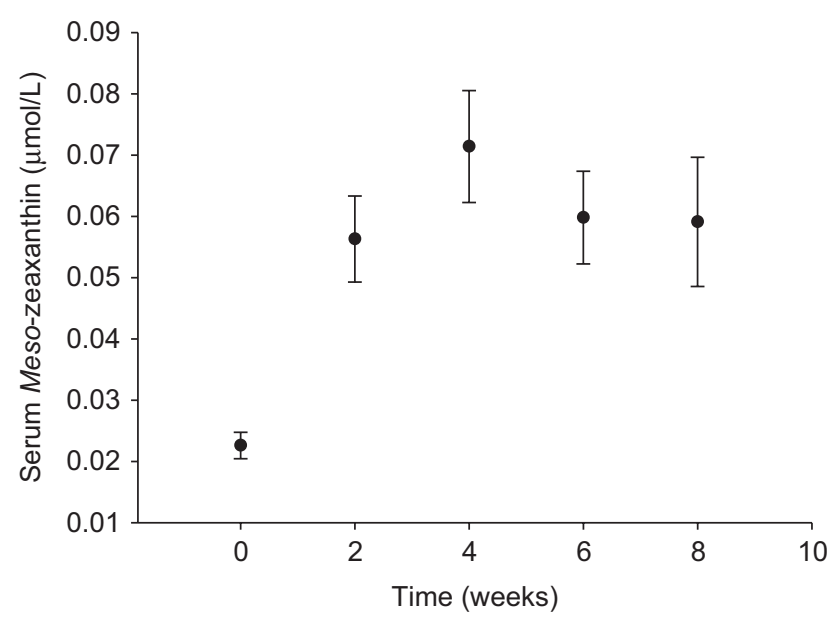

FIGURE 5 Mean ( \pm standard error) serum meso-zeaxanthin concentrations for 10 subjects over the 8-week study period.

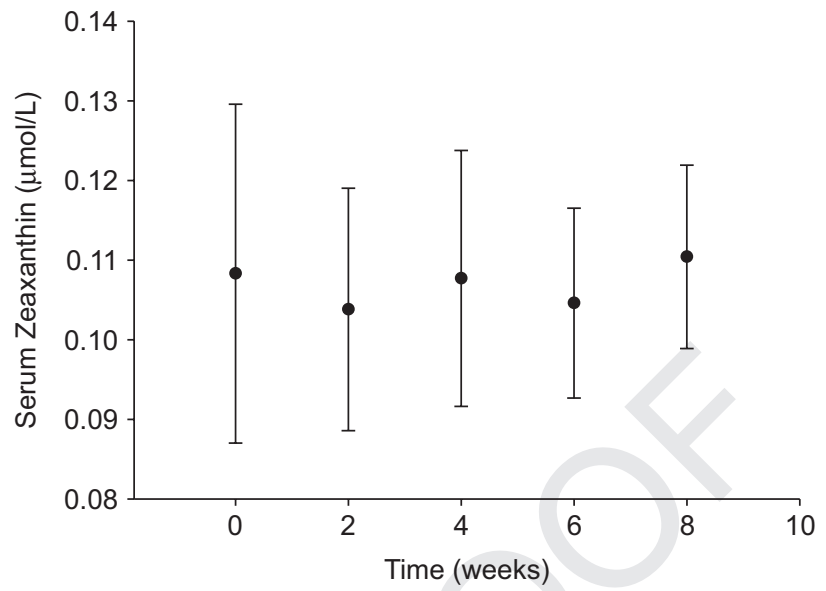

FIGURE 6 Mean ( \pm standard error) serum zeaxanthin concentrations for 10 subjects over the 8-week study period.

TABLE 5 Individual serum concentrations for total lutein, total zeaxanthin, meso-zeaxanthin, and zeaxanthin at each study visit

\begin{tabular}{|c|c|c|c|c|c|c|c|c|c|c|c|c|c|c|c|c|c|c|c|c|c|}
\hline & \multirow[b]{2}{*}{ Group } & \multicolumn{4}{|c|}{ V1 } & \multicolumn{4}{|c|}{$\mathrm{V} 2$} & \multicolumn{4}{|c|}{ V3 } & \multicolumn{4}{|c|}{$\mathrm{V} 4$} & \multicolumn{4}{|c|}{ V5 } \\
\hline & & $\mathrm{L}$ & ZT & $\mathrm{MZ}$ & Z & $\mathrm{L}$ & $\mathrm{ZT}$ & $\mathrm{MZ}$ & Z & $\mathrm{L}$ & $\mathrm{ZT}$ & $\mathrm{MZ}$ & Z & L & $\mathrm{ZT}$ & $\mathrm{MZ}$ & Z & $\mathrm{L}$ & $\mathrm{ZT}$ & $\mathrm{MZ}$ & Z \\
\hline 1 & Normal & 0.30 & 0.18 & 0.03 & 0.15 & 0.29 & 0.17 & 0.03 & 0.13 & 0.34 & 0.22 & 0.06 & 0.17 & 0.34 & 0.21 & 0.06 & 0.14 & 0.33 & 0.18 & 0.07 & 0.11 \\
\hline 2 & & .25 & .13 & 0.02 & .11 & 36 & 18 & 0.07 & 0.11 & 0.37 & 0.20 & 0.08 & 0.12 & 0.25 & 0.14 & 0.03 & 0.11 & 0.25 & 0.12 & 0.03 & 0.09 \\
\hline 3 & & 0.29 & 0.13 & 0.02 & 0.11 & 0.35 & 0.15 & 0.05 & 0.11 & 0.32 & 0.14 & 0.06 & 0.08 & 0.34 & 0.16 & 0.07 & 0.09 & 0.31 & 0.14 & 0.04 & 0.10 \\
\hline 4 & Nor & 0.27 & 0.11 & 0.02 & 0.09 & 0.46 & 0.23 & 0.09 & 0.13 & 0.59 & 0.23 & 0.11 & 0.12 & 0.45 & 0.20 & 0.08 & 0.12 & 0.55 & 0.24 & 0.12 & 0.12 \\
\hline 5 & Nor & 0.46 & 0.30 & 0.03 & 0.27 & 0.55 & 0.28 & 0.08 & 0.20 & 0.62 & 0.32 & 0.11 & 0.21 & 0.51 & 0.27 & 0.09 & 0.18 & 0.49 & 0.27 & 0.07 & 0.20 \\
\hline 6 & AMD & 0.49 & 0.14 & 0.03 & 0.11 & 0.55 & 0.18 & 0.07 & 0.11 & 0.58 & 0.20 & 0.10 & 0.10 & 0.58 & 0.20 & 0.10 & 0.10 & 0.53 & 0.22 & 0.12 & 0.10 \\
\hline 7 & & 0.22 & 0.10 & 0.02 & 0.08 & 0.31 & 0.15 & 0.06 & 0.09 & 0.34 & 0.16 & 0.07 & 0.09 & 0.29 & 0.14 & 0.05 & 0.09 & 0.32 & 0.16 & 0.04 & 0.11 \\
\hline 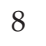 & & 0.31 & 0.10 & 0.04 & 0.07 & 0.32 & 0.13 & 0.06 & 0.07 & 0.39 & 0.17 & 0.06 & 0.11 & 0.39 & 0.14 & 0.06 & 0.09 & 0.34 & 0.14 & 0.04 & 0.10 \\
\hline 9 & AMD & 0.16 & 0.05 & 0.02 & 0.03 & 0.24 & 0.07 & 0.03 & 0.04 & 0.19 & 0.06 & 0.03 & 0.03 & 0.18 & 0.07 & 0.03 & 0.04 & 0.22 & 0.09 & 0.03 & 0.06 \\
\hline 10 & AMD & 0.27 & 0.07 & 0.02 & 0.05 & 0.23 & 0.07 & 0.03 & 0.04 & 0.30 & 0.09 & 0.03 & 0.06 & 0.33 & 0.14 & 0.04 & 0.10 & 0.27 & 0.14 & 0.03 & 0.11 \\
\hline
\end{tabular}

Values represent mean in $\mu \mathrm{mol} / \mathrm{L} ; \mathrm{N}=10 ; \mathrm{S}=$ Subject; $\mathrm{V} 1=$ visit $1, \mathrm{~V} 2=$ visit 2, V3=visit 3, V4=visit 4, V5=visit 5; TL=total lutein, $\mathrm{TZ}=$ total zeaxanthin, $\mathrm{MZ}=$ meso-zeaxanthin, $\mathrm{Z}=$ zeaxanthin; Group: 1: Normal; 2: AMD.

TABLE 6 Average macular pigment optical density at each degree of eccentricity for all subjects

\begin{tabular}{lcccccc}
\hline MPOD & V1 & V2 & V3 & V4 & V5 & $p$-Value \\
\hline 0.25 & $0.39 \pm 0.19$ & $0.49 \pm 0.18$ & $0.52 \pm 0.22$ & $0.57 \pm 0.26$ & $0.61 \pm 0.26$ & $\mathrm{p}<0.017$ \\
0.5 & $0.38 \pm 0.16$ & $0.43 \pm 0.15$ & $0.46 \pm 0.16$ & $0.44 \pm 0.18$ & $0.45 \pm 0.18$ & $\mathrm{p}<0.101$ \\
1.0 & $0.26 \pm 0.15$ & $0.29 \pm 0.14$ & $0.32 \pm 0.10$ & $0.32 \pm 0.17$ & $0.38 \pm 0.14$ & $\mathrm{p}>0.030$ \\
1.75 & $0.14 \pm 0.10$ & $0.17 \pm 0.10$ & $0.17 \pm 0.06$ & $0.16 \pm 0.08$ & $0.16 \pm 0.09$ & $\mathrm{p}>0.610$ \\
Total average & $0.29 \pm 0.13$ & $0.34 \pm 0.12$ & $0.37 \pm 0.12$ & $0.37 \pm 0.15$ & $0.40 \pm 0.15$ & $\mathrm{p}<0.019$ \\
\hline
\end{tabular}

Values represent mean \pm SD; $N=9$ (as one subject, 10, was unable to use the Densitometer and was, therefore, unable to have her MPOD measured); $\mathrm{MPOD}=$ macular pigment optical density; $\mathrm{V} 1=$ visit $1, \mathrm{~V} 2=$ visit $2, \mathrm{~V} 3=$ visit $3, \mathrm{~V} 4=\mathrm{visit} 4, \mathrm{~V} 5=\mathrm{visit} 5 ; 0.25=0.25^{\circ}$ retinal eccentricity; $0.5=0.5^{\circ}$ retinal eccentricity; $1.0=1^{\circ}$ retinal eccentricity; $1.75=1.75^{\circ}$ retinal eccentricity; Total average $=$ average MPOD for all eccentricities. The $p$-values represent repeated measures ANOVA for the 5 study visits, with Huynh-Feldt corrections for lack of sphericity.

\section{The Relationship between Alterations in MPOD Spatial Profile and Alterations in Serum Carotenoid Concentrations}

In this study, the following all showed significant increases with time: serum MZ, serum TL, and serum $\mathrm{TZ}, \mathrm{MPOD}$ at eccentricities at $0.25^{\circ}, 1^{\circ}$, and also average MPOD across the retina (i.e., $0.25^{\circ}, 0.5^{\circ}, 1^{\circ}, 1.75^{\circ}$ ) (see repeated measures results above, Figures 3, 4, 5, and Tables 4 and 6, respectively).
However, investigating change in serum concentrations (for V2-V1) in each of MZ, TL, and TZ with respect to change in MPOD at $0.25^{\circ}, 1^{\circ}$, and average MPOD, we found that, in every case, there is an inverse correlation between these variables $(r=-0.538$ to -0.805 , e.g., V2-V1 serum concentrations of MZ vs. V2-V1 MPOD at $0.25^{\circ}: r=-0.538, p=0.135$, Figure $8 \mathrm{~A}$ ). The fact that some of these correlations were not statistically significant can be ascribed to the small sample size of the current study. Of note, the strongest inverse 
correlation was seen for $\mathrm{TZ}(\mathrm{MZ}+\mathrm{Z}$ combined), which was statistically significant $(r=-0.805, p=0.009)$.

Interestingly, however, and for MZ only, the correlation is much closer to zero when we compare V5-V1 change rather than V2-V1 change (i.e., V5-V1 serum concentrations of MZ vs V5-V1 MPOD at $0.25^{\circ}$ : $r=-0.028, p=0.943$, Figure 8B); whereas, for TL and TZ the change in serum concentrations of these carotenoids versus the change in MPOD at $0.25^{\circ}$ remained inverse at visit 5 ( $r=-0.434$ and -0.671 , respectively).

\section{Typical versus Atypical MPOD Spatial Profile}

Recent studies have been concerned with the spatial profile and distribution of MPOD. ${ }^{30,35-38}$ Of note, in the present study, four subjects (one Normal subject [Group 1]-Subject 5; and three AMD subjects [Group 2]-Subjects 6, 7, and 9) who displayed an atypical MPOD spatial profile at baseline (i.e., presupplementation), had the more typical MPOD spatial profile (i.e., highest MPOD at the center) after eight weeks of supplementation with $\mathrm{MZ}, \mathrm{L}$, and $\mathrm{Z}$ (i.e., the formulation used in this study). The MPOD spatial profile, averaged for the above four subjects, at pre(baseline) and post-supplementation (after 8 weeks) is presented in Figure 9 and their individual spatial profiles, at these two time points, are presented in Figure 10.

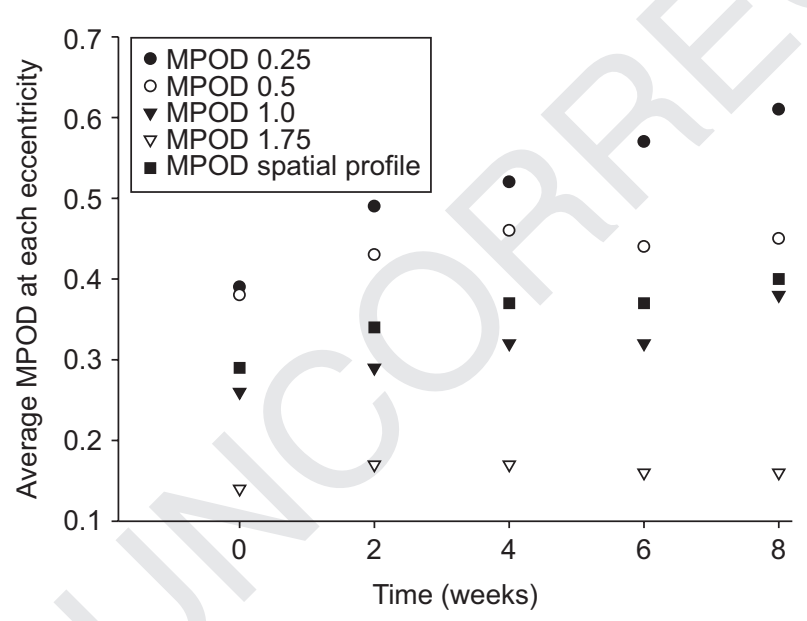

FIGURE 7 Values presented $=$ mean; $N=9$ subjects (as one subject, 10, was unable to use the densitometer and was therefore unable to have her MPOD measured); MPOD = macular pigment optical density; MPOD $0.25=\mathrm{MPOD}$ measured at $0.25^{\circ}$ retinal eccentricity; MPOD 0.5 $=$ MPOD measured at $0.5^{\circ}$ retinal eccentricity; MPOD 1.0 $=$ MPOD measured at $1.0^{\circ}$ retinal eccentricity; MPOD 1.75 $=$ MPOD measured at $1.75^{\circ}$ retinal eccentricity; MPOD spatial profile $=$ average MPOD of all degrees of retinal eccentricity $\left(0.25^{\circ}, 0.5^{\circ}, 1.0^{\circ}\right.$, and $1.75^{\circ}$ of retinal eccentricity).

\section{DISCUSSION}

The MOST study was designed to investigate macular and serum responses to supplementation with the three macular carotenoids (in which MZ predominates: $7.3 \mathrm{mg}$ of $\mathrm{MZ}, 3.7 \mathrm{mg}$ of $\mathrm{L}$, and $0.8 \mathrm{mg}$ of $\mathrm{Z}$ ), in normal healthy subjects and patients with early AMD. MPOD was measured using $\mathrm{CHFP}$ at $0.25^{\circ}, 0.5^{\circ}, 1^{\circ}$, and $1.75^{\circ}$ retinal eccentricity with a reference point at $7^{\circ}$, every two weeks over a 60 day (two months) study period. A blood sample was also collected at each study visit in order to analyze serum concentrations of MZ, TL, $\mathrm{TZ}$, and $\mathrm{Z}$.

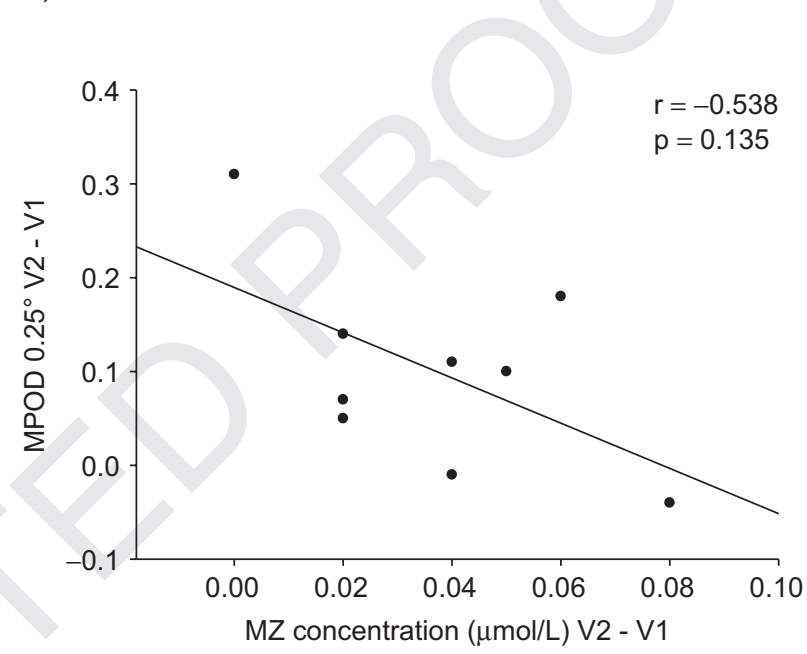

FIGURE 8A MPOD=macular pigment optical density; MPOD v2-v1 = macular pigment optical density at visit 2 minus macular pigment optical density at visit 1 .

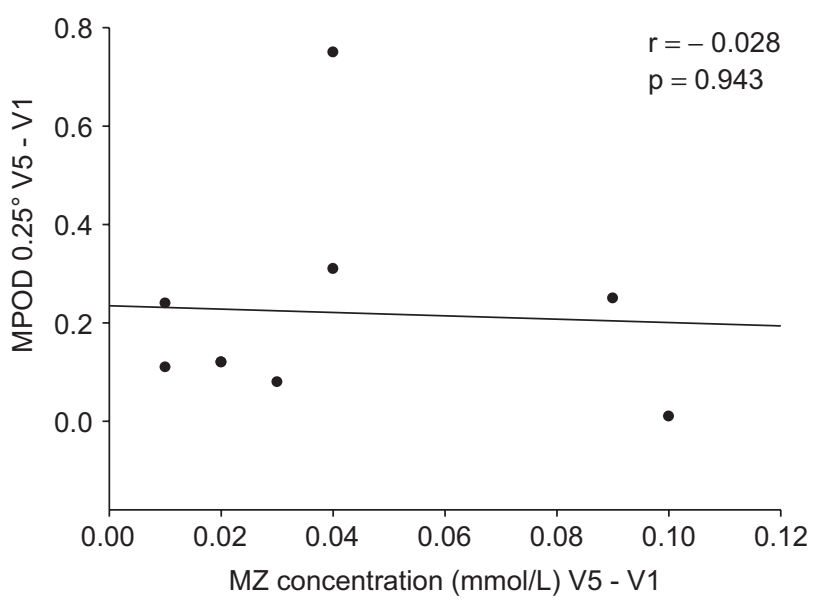

FIGURE 8B $N=9$ (as one subject, 10, was unable to use the densitometer and was, therefore, unable to have her MPOD measured); $\mathrm{MPOD}=$ macular pigment optical density; MPOD v5-v1 = macular pigment optical density at visit 5 minus macular pigment optical density at visit 1 . Of note, two subjects ( 3 and 7 ) demonstrated the same change in MZ $(0.01 \mu \mathrm{mol} / \mathrm{L})$ and MPOD (0.12), and, therefore, it appears that there are only eight data points on this graph. 
Supplementation studies to date have previously reported on serum response to supplementation with the macular carotenoids, with the majority of these studies reporting significant increases in serum concentrations of L and/or Z following supplementation with these carotenoids. ${ }^{22,23,25,27,39-52}$ Consistent with these previous studies, we report statistically significant increases in $\mathrm{MZ}$ and TL, after just two weeks of supplementation. Of note, average serum TL concentrations exhibited the highest average increase following supplementation with the study formulation, when compared to the other carotenoids (MZ and TZ). Our findings of a 1.3-fold increase in serum concentrations of $\mathrm{L}$ are consistent with previous studies, as our study formulation contained only $3.7 \mathrm{mg}$. For example, Bone et al. supplemented two subjects with $5 \mathrm{mg}$ of $\mathrm{L}$ per day for 120 days and reported a 3-fold increase in serum concentrations of this carotenoid. ${ }^{51}$ Similarly, Berendschot et al. supplemented 8 subjects with $10 \mathrm{mg}$ of L per day for 12 weeks and reported a 5 -fold increase in serum concentrations of this carotenoid. ${ }^{39}$

In our study, serum concentrations of $Z$ showed no significant increase over the study period, and this may be attributable to the low amount of $\mathrm{Z}$ in the formulation (only $0.8 \mathrm{mg}$ per capsule). Previous studies have reported significant increases in serum concentrations of $\mathrm{Z}$ following supplementation, albeit with a higher concentration of this carotenoid (e.g., Schalch et al. (2007): $12.6 \mathrm{mg} \mathrm{Z}$ for 17 weeks showed an increase of $\sim 1.09 \mu \mathrm{mol} / \mathrm{L}$; Bone et al. (2003): $30 \mathrm{mg}$ of $Z$ for

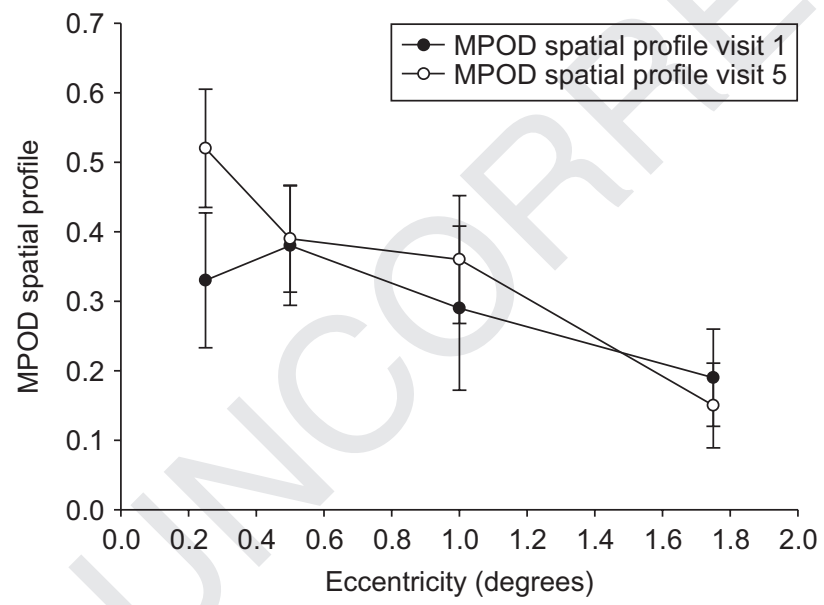

FIGURE 9 Mean macular pigment optical density spatial profile for four subjects at visit 1 (pre-supplementation) who displayed the atypical MPOD spatial profile and for the same four subjects at visit 5 (after 8 weeks of supplementation) having augmented their central MPOD. Mean ( \pm standard error); $N=4$ ( 1 normal subject and 3 AMD subjects); Visit $1=$ average macular pigment optical density of four atypical subjects at baseline; visit $5=$ average macular pigment optical density of same four subjects at week 8 (post supplementation). one year showed an increase of $0.52 \mu \mathrm{mol} / \mathrm{L}$ ) in the preparation. ${ }^{43,51}$

We report a statistically significant increase in serum concentrations of MZ, with a 3-fold increase observed over the 8-week study period (i.e., mean MZ: V1 $=0.02$ $\mu \mathrm{mol} / \mathrm{L}$; mean MZ V2 $=0.06 \mu \mathrm{mol} / \mathrm{L})$. However, it is important to point out that while $\mathrm{MZ}$ demonstrated a 3 -fold increase in serum (from its baseline value), that following supplementation, when absolute average MZ serum concentrations are compared with average absolute serum L concentrations, we see that there is significantly more circulating $\mathrm{L}$ than $\mathrm{MZ}$ in serum (mean \pm SD: $0.36 \pm 0.12 \mu \mathrm{mol} / \mathrm{L}$ versus $0.06 \pm 0.03$ for $\mathrm{L}$ and $\mathrm{MZ}$, respectively). Also, when our concentration increase is compared to the studies carried out by Thurnham et al. and Bone et al., it can be seen that our serum MZ response was much lower when compared to those studies (i.e., mean \pm SD serum MZ concentration $\mu \mathrm{mol} / \mathrm{L}=0.209 \pm 0.128$ and $0.094 \pm 0.071$, respectively. However, it should be noted that the supplement used in the study by Thurnham et al. was suspended in oil; whereas, our study used a microencapsulated form of the supplement suspended in starch, which may account for, at least in part, the low serum response reported here, given that oil has been shown to promote carotenoid absorption. ${ }^{53}$

The investigation by Thurnham et al. (2008) reported an average increase of $0.209 \pm 0.128 \mu \mathrm{mol} / \mathrm{L}$ in serum concentrations of MZ (following supplementation with $8 \mathrm{mg}$ per day of this carotenoid over a 22-day study period). ${ }^{27}$ Similarly, the study by Bone et al. observed augmented average serum concentrations of $\mathrm{MZ}$ $(0.094 \pm 0.071 \mu \mathrm{mol} / \mathrm{L})$ following supplementation with $14 \mathrm{mg}$ per day of this carotenoid over a 120-day period. ${ }^{25}$

The study, conducted by Thurnham et al. (2008), reported on the absorption of MZ following supplementation with this carotenoid. Also, they compared the plasma responses to supplementation with a formulation containing MZ (Lutein Plus ${ }^{\circledR}$ ) with formulations containing $\mathrm{L}$ and $\mathrm{Z}$ (but not MZ), and reported that the increases seen in plasma $\mathrm{L}$ and $\mathrm{Z}$ concentrations were similar for each formulation, suggesting that $M Z$ has little effect on absorption of L and/or Z. However, although Thurnham et al. reported that MZ did not decrease the absorption of $\mathrm{L}$ and $\mathrm{Z}$, it is important to note that the study formulation used in that study contained more L than MZ (8mg MZ, $10.8 \mathrm{mg} \mathrm{L}$ and $1.2 \mathrm{mg} \mathrm{Z}$ ); whereas, in our study, the formulation contained more $\mathrm{MZ}$ than L (i.e., $7.3 \mathrm{mg} \mathrm{MZ}, 3.8 \mathrm{mg} \mathrm{L}$ and $0.8 \mathrm{mg} \mathrm{Z}$ ). Thus, it may not be possible to extrapolate directly the effects of $\mathrm{MZ}$ on the absorption of $\mathrm{L}$ and $\mathrm{Z}$ to our study without further work. Of note, the studies conducted by Thurnham et al. and Bone et al. are the only two studies to date that have investigated serum 

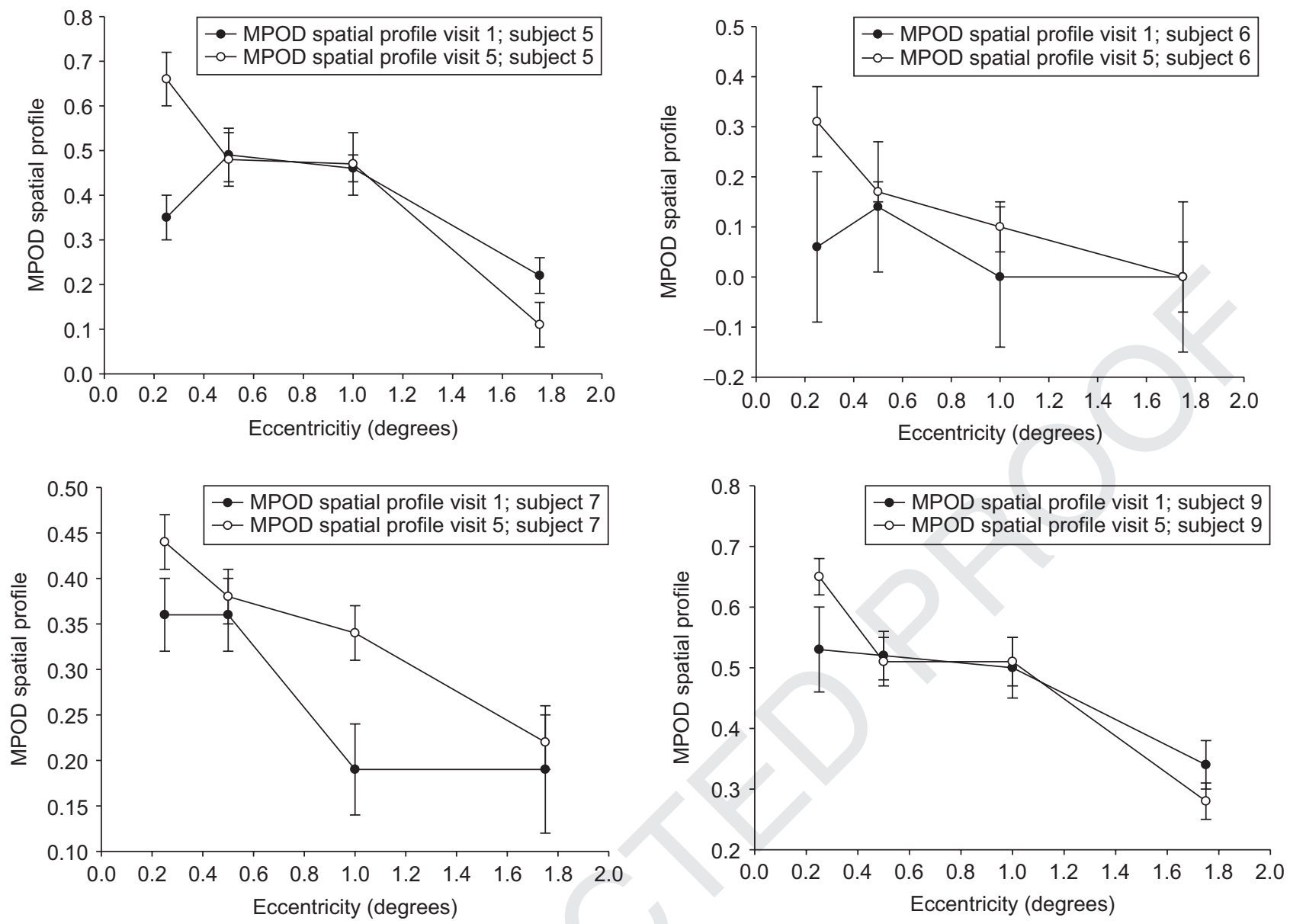

FIGURE 10 Individual macular pigment optical density spatial profiles for subjects 5, 6, 7 and 9 at visit 1 (pre-supplementation) who displayed the atypical MPOD spatial profile and for the same four subjects at visit 5 (after 8 weeks of supplementation) having augmented their central MPOD. Data presented here $=$ mean $( \pm$ standard deviation); subject $5=$ normal group subject; subjects 6, 7, and 9=AMD group subjects.

carotenoid response following supplementation with a preparation containing $\mathrm{MZ}$, making any discussion with respect to our finding difficult. ${ }^{25,27}$ Also, no study to date has investigated and/or reported on histology or retinal function in response to $\mathrm{MZ}$ supplementation.

To our knowledge, no study to date has reported the presence of MZ in human serum pre-supplementation with this carotenoid. This notion is unsurprising, given that $\mathrm{MZ}$ is not found in a typical western diet (with the exception of some unusual foods and shellfish). ${ }^{20}$ However, in this current study, we detected the possible presence of $\mathrm{MZ}$, albeit in minute concentrations, in all 10 subjects (mean \pm SD MZ in $\mu \mathrm{mol} / \mathrm{L}: 0.023 \pm 0.007$ ). The possibility that $\mathrm{MZ}$ was in serum at baseline is a novel and interesting finding and may be explained as follows: MZ may be present in carotenoid-containing foods but as chiral chromatography is needed to separate $M Z$ from $Z, M Z$ may not have been detected since it is rarely used. Alternatively, MZ may be generated in serum following $\mathrm{L}$ transformation. However, the paucity of studies investigating any aspect of $\mathrm{MZ}$ in the diet and/or serum renders any discussion with respect to our finding that $\mathrm{MZ}$ is present in the serum of unsupplemented subjects difficult, and further study is warranted to fully investigate this assumption.

This current study is the first investigation into the spatial profile of MPOD (i.e., at $0.25^{\circ}, 0.5^{\circ}, 1^{\circ}, 1.75^{\circ}$ ) following supplementation with all three macular carotenoids (MZ, L, and $\mathrm{Z}$ ), which enabled us to measure change, if any, at the above degrees of retinal eccentricity, including the more central locations where $\mathrm{MZ}$ is located. ${ }^{18}$ We report increases in MPOD at $0.25^{\circ}, 0.5^{\circ}, 1^{\circ}$, and average MPOD across the retina (i.e., average of $0.25^{\circ}, 0.5^{\circ}, 1^{\circ}$, and $1.75^{\circ}$ ) during the study period, which became significant after just two weeks of supplementation. The rapid increase seen in MPOD in the current study is a somewhat novel finding as, to our knowledge, previous studies have not measured and/or reported on MPOD after two weeks of supplementation. In other words, previous studies to date have only reported on change in MP 
levels, if any, after four weeks of supplementation and beyond.

Our findings are consistent with a study conducted by Hammond et al. (1997), who reported significant MPOD augmentation following dietary modification (i.e., corn $0.4 \mathrm{mg} \mathrm{L}$ and $0.3 \mathrm{mg} \mathrm{Z}$ and spinach $10.8 \mathrm{mg}$ $\mathrm{L}$ and $0.3 \mathrm{mg} \mathrm{Z}$ ) after just four weeks of dietary intervention..$^{22}$ Our observation is also consistent with previous reports that have investigated MP response to macular carotenoid supplementation (Table 1). In contrast, however, we found no significant augmentation of MPOD at $1.75^{\circ}$ eccentricity. Also, and of interest, we observed the greatest increase in MPOD at $0.25^{\circ}$, with a mean \pm SD increase of $0.16 \pm 0.05$ ODU at this eccentricity. Of note, no study to date has measured MPOD at this eccentricity following supplementation with $\mathrm{MZ}, \mathrm{L}$, and $\mathrm{Z}$, and, therefore, it is difficult to make direct comparisons with other reports. It is likely that the significant increase seen in central MPOD in this study may be due to either MZ and/or $\mathrm{L}$, especially given that $\mathrm{MZ}$ and L demonstrated significant responses in serum concentrations; however, with respect to $M Z$, this novel finding is interesting given that $\mathrm{MZ}$ is the dominant carotenoid in the study formulation (i.e., $7.3 \mathrm{mg}[62 \%]$ ) and given that the ratio of $\mathrm{MZ}$ to $\mathrm{L}$, and the ratio of $\mathrm{MZ}$ to $\mathrm{Z}$, is greater at the center of the fovea. For example, in 1997, Bone et al. reported that the proportions of $\mathrm{MZ}: \mathrm{Z}$ in the central $3 \mathrm{~mm}$ of the macula was 0.83 which decreased with increasing distance from the fovea. ${ }^{18}$ Also, it is important to note that although the mean concentration of MZ was only $0.06 \mathrm{umol} / \mathrm{L}$ at visit 2 , this represents $\sim 160 \times 10^{3} \mathrm{ng}$ of $\mathrm{MZ}$ per 5 liters of blood. This observation is important, given that the amount of $\mathrm{MZ}$ in human donor eyes has been reported as $\sim 7.7 \mathrm{ng}$ and also given that an active binding protein for $\mathrm{Z}$ and MZ have been identified in retinal tissue. ${ }^{53-55}$ There has only been one other study to date that has measured MPOD following daily supplementation with MZ. That study, recently performed by Bone et al., in 2007, included 10 normal subjects, who were supplemented with $14.9 \mathrm{mg}$ of $\mathrm{MZ}, 5.5 \mathrm{mg}$ of $\mathrm{L}$, and $1.4 \mathrm{mg}$ of $\mathrm{Z}$, for 120 days. Bone and co-workers reported a significant increase in MPOD at $0.75^{\circ}$ of retinal eccentricity (mean increase $=0.07 \mathrm{ODU}$ at this eccentricity) over the study period; however, in their study, MP was measured at only one retinal location $\left(0.75^{\circ}\right) .^{25}$

As mentioned above, previous studies reporting on MPOD response to supplemental $\mathrm{L}$ and $\mathrm{Z}$ have reported parallel increases between these variables. In 1997, Hammond et al. showed MPOD augmentation following dietary modification after four weeks. Interestingly, two of the 11 subjects in that study did not respond at the macula, despite a significant increase found in serum concentrations of $\mathrm{L}$ and $\mathrm{Z}$. Hammond et al. referred to these subjects as "retinal non-responders." 22 Our findings are consistent with this, we found that one of the 10 subjects recruited (Subject 4 ) into our trial did not respond at the macula, despite significant increases found in serum concentrations of MZ and L. In fact, and of particular interest, this subject displayed one of the highest increases in serum macular carotenoid concentrations. Also, this subject displayed a "typical" MPOD spatial profile and had the highest MPOD level (of subjects in this study), at baseline (i.e., 0.72 ODU at $0.25^{\circ}$ retinal eccentricity). It is possible that this subject's macula was saturated with MP, thus precluding the possibility of MP augmentation in response to supplementation. However, a longer supplementation period and follow-up may have resulted in MPOD augmentation for this subject.

Unexpectedly, we report an inverse trend between rises in serum concentrations of $\mathrm{MZ}, \mathrm{TL}$, and $\mathrm{TZ}$ (V2-V1) and increases in MPOD at $0.25^{\circ}, 0.5^{\circ}, 1^{\circ}$ eccentricity and in average MPOD across the retina (V2-V1). Interestingly, however, this trend disappeared when we investigated the relationship between change in MPOD (at $0.25^{\circ}$ ) from V5 and V1 and change in serum $\mathrm{MZ}$ from V5 and V1, whereas, it remained inverse for the relationship between change in $\operatorname{MPOD}\left(\right.$ at $0.25^{\circ}$ ) from V5 and V1 and change in serum TL and TZ from V5 and V1. This somewhat unexpected and apparently contradictory finding may simply be explained by the fact that circulating MZ was captured by tissues more rapidly in subjects with depleted levels of this carotenoid at the macula and/or other target tissues (e.g., fat cells). This hypothesis is supported by our finding that the observed inverse trend between change in MPOD and change in serum MZ did not persist beyond V3. The above findings must, however, be interpreted with appreciation of the small sample size of our study and further study into this relationship is merited.

Another interesting finding from our study was the observation that four subjects (one normal and three AMD) exhibited an atypical MPOD spatial profile at baseline (i.e., secondary peak). Interestingly, however, following supplementation with $\mathrm{MZ}$, all subjects exhibited the more typical MPOD spatial profile (exponential like decline), ,,12 after just eight weeks of supplementation. In other words, it is tempting to hypothesise that the subjects who displayed the atypical MPOD spatial profile at baseline were exhibiting a relative lack of MP centrally (and, therefore, MZ), perhaps due to an inability to convert $\mathrm{L}$ to $\mathrm{MZ}$ at this location, but were able to rebuild their central MP peak with a supplement containing MZ.

While our findings are interesting, it is important to note the limitations inherent in our study design, and these include: the sample size of this trial was small 
$(n=10)$, it was a non-blind open-labeled study, and the period of follow-up was only 8 weeks (60 days). Currently we are awaiting the results of a double blind, randomized, placebo controlled trial (MOST 2 [ISRCTN60816411]) investigating serum and macular response, in a normal healthy population, to a supplement containing the three macular carotenoids $(10.6 \mathrm{mg}$ of $\mathrm{MZ}, 5.9 \mathrm{mg}$ of $\mathrm{L}$, and $1.2 \mathrm{mg}$ of $\mathrm{Z}$ ). Also, a second pilot study, in AMD patients over a longer period of time will compare a formulation of $\mathrm{L}$ and $\mathrm{Z}$ only, with a formulation of all three macular carotenoids $(\mathrm{MZ}, \mathrm{L}$, and $\mathrm{Z}$ ), and a follow-up on double blind randomized trial comparing these formulations is also envisaged. This study will further enhance our understanding of serum and macular response to supplements containing the macular carotenoids in both normal and AMD subjects.

In conclusion, we report significant increases in serum concentrations of the macular carotenoids following supplementation with a formulation containing $7.3 \mathrm{mg} \mathrm{MZ}, 3.7 \mathrm{mg} \mathrm{L}$, and $0.8 \mathrm{mg} \mathrm{Z}$ and also a significant increase in MPOD (and alteration of its spatial profile). Also, this pilot study has identified the presence of MZ in human serum pre-supplementation, and the ability of this carotenoid formulation to rebuild central MPOD in subjects who display atypical profiles at baseline.

\section{ACKNOWLEDGMENTS}

This study was supported by a grant from The Howard Foundation, Cambridge, CB22 5LA, United Kingdom. We thank Mr. Jonathon Oates, Head of Pharmacy, Waterford Regional Hospital, Dunmore Road, Waterford, Ireland for his help in labeling and packaging the study capsules.

AQ3 Declaration of interest: The authors report no conflict of interest. The authors alone are responsible for the content and writing of the paper.

\section{REFERENCES}

[1] Bressler NM. Age-related macular degeneration is the leading cause of blindness. JAMA. 2004;291:1900-1901.

[2] Congdon NG, Friedman DS, Lietman T. Important causes of visual impairment in the world today. JAMA. 2003;290:20572060.

[3] Friedman DS, O'Colmain BJ, Munoz B, et al. Prevalence of age-related macular degeneration in the United States. Arch Ophthalmol. 2004;122:564-572.

[4] Rein DB, Wittenborn JS, Zhang X, et al. Forecasting agerelated macular degeneration through the year 2050: The potential impact of new treatments. Arch Ophthalmol. 2009;127:533-540.
[5] Beatty S, Koh HH, Henson D, et al. The role of oxidative stress in the pathogenesis of age-related macular degeneration. Surv Ophthalmol. 2000;45:115-134.

[6] $\mathrm{Wu}$ J, Seregard S, Algvere PV. Photochemical damage of the retina. Surv Ophthalmol. 2006;51:461-481.

[7] Loane E, Kelliher C, Beatty S, et al. The rationale and evidence base for a protective role of macular pigment in agerelated maculopathy. Br J Ophthalmol. 2008;92:1163-1168.

[8] Bone RA, Landrum JT, Hime GW, et al. Stereochemistry of the human macular carotenoids. Invest Ophthalmol Vis Sci. 1993;34:2033-2040.

[9] Bone RA, Landrum JT, Tarsis SL. Preliminary identification of the human macular pigment. Vision Res. 1985;25:1531-1535.

[10] Snodderly DM, Brown PK, Delori FC, et al. Macular Pigment. 1. Absorbance spectra, localization, and discrimination from other yellow pigments in primate retinas. Invest Ophthalmol Vis Sci. 1984;25:660-673.

[11] Sujak A, Gabrielska J, Grudzinski W, et al. Lutein and zeaxanthin as protectors of lipid membranes against oxidative damage: The structural aspects. Arch Biochem Biophys. 1999;371:301-307.

[12] Snodderly DM, Auran JD, Delori FC. The macular pigment. II. Spatial distribution in primate retinas. Invest Ophthalmol Vis Sci. 1984;25:674-685.

[13] Junghans A, Sies H, Stahl W. Macular pigments lutein and zeaxanthin as blue light filters studied in liposomes. Arch Biochem Biophys. 2001;391:160-164.

[14] Stringham JM, Hammond BR, Wooten BR, et al. Compensation for light loss resulting from filtering by macular pigment: Relation to the S-cone pathway. Optom Vis Sci. 2006;83:887-894.

[15] Siems WG, Sommerburg O, van Kuijk FJ. Lycopene and beta-carotene decompose more rapidly than lutein and zeaxanthin upon exposure to various pro-oxidants in vitro. Biofactors. 1999;10:105-113.

[16] Khachik F, Bernstein PS, Garland DL. Identification of lutein and zeaxanthin oxidation products in human and monkey retinas. Invest Ophthalmol Vis Sci. 1997;38:1802-1811.

[17] Sommerburg O, Keunen JEE, Bird AC, et al. Fruits and vegetables that are sources for lutein and zeaxanthin: The macular pigment in human eyes. Br J Ophthalmol. 1998;82:907-910.

[18] Bone RA, Landrum JT, Friedes LM, et al. Distribution of lutein and zeaxanthin stereoisomers in the human retina. Exp Eye Res. 1997;64:211-218.

[19] Johnson EJ, Neuringer M, Russell RM, et al. Nutritional manipulation of primate retinas. III: Effects of lutein or zeaxanthin supplementation on adipose tissue and retina of xanthophyll-free monkeys. Invest Ophthalmol Vis Sci. 2005;46:692-702.

[20] Maoka T, Arai A, Shimizu M, et al. The first isolation of enantiomeric and meso-zeaxanthin in nature. Comp Biochem Physiol B. 1986;83:121-124.

[21] Trieschmann M, Spital G, Lommatzsch A, et al. Macular pigment: Quantitative analysis on autofluorescence images. Grae Arch Clin Exp Ophthalmol. 2003;241:1006-1012.

[22] Hammond BR, Johnson EJ, Russell RM, et al. Dietary modification of human macular pigment density. Invest Ophthalmol Vis Sci. 1997;38:1795-1801.

[23] Landrum JT, Bone RA, Joa H, et al. A one year study of the macular pigment: The effect of 140 days of a lutein supplement. Exp Eye Res. 1997;65:57-62.

[24] Trieschmann M, Beatty S, Nolan JM, et al. Changes in macular pigment optical density and serum concentrations of its constituent carotenoids following supplemental lutein and zeaxanthin: The LUNA study. Exp Eye Res. 2007;84:718-728. 
[25] Bone RA, Landrum JT, Cao Y, et al. Macular pigment response to a supplement containing meso-zeaxanthin, lutein and zeaxanthin. Nutr Metab (Lond). 2007;4:12.

[26] Bird AC, Bressler NM, Bressler SB, et al. An international classification and grading system for age-related maculopathy and age-related macular degeneration. The International ARM Epidemiological Study Group. Surv Ophthalmol. 1995;39:367-374.

[27] Thurnham DI, Tremel A, Howard AN. A supplementation study in human subjects with a combination of meso-zeaxanthin, $\left(3 \mathrm{R}, 3^{\prime} \mathrm{R}\right)$-zeaxanthin and $\left(3 \mathrm{R}, 3^{\prime} \mathrm{R}, 6^{\prime} \mathrm{R}\right)$-lutein. $\mathrm{Br} \mathrm{J}$ Nutr. 2008.

[28] Wooten BR, Hammond BR, Land RI, et al. A practical method for measuring macular pigment optical density. Invest Ophthalmol Vis Sci. 1999;40:2481-2489.

[29] Loane E, Stack J, Beatty S, et al. Measurement of macular pigment optical density using two different heterochromatic flicker photometers. Curr Eye Res. 2007;32:555-564.

[30] Kirby ML, Galea M, Loane E, et al. Foveal anatomic associations with the secondary peak and the slope of the macular pigment spatial profile. Invest Ophthalmol Vis Sci. 2008.

[31] Stringham JM, Hammond BR, Nolan JM, et al. The utility of using customized heterochromatic flicker photometry (cHFP) to measure macular pigment in patients with age-related macular degeneration. Exp Eye Res. 2008;87:445-453.

[32] Falsini B, Fadda A, Iarossi G, et al. Retinal sensitivity to flicker modulation: Reduced by early age-related maculopathy. Invest Ophthalmol Vis Sci. 2000;41:1498-1506.

[33] Tyler CW. Two processes control variations in flicker sensitivity over the life span. J Opt Soc Am A. 1989;6:481-490.

[34] Bone RA, Landrum JT, Gibert JC. Macular pigment and the edge hypothesis of flicker photometry. Vision Res. 2004;44:3045-3051.

[35] Delori FC, Goger DG, Keilhauer C, et al. Bimodal spatial distribution of macular pigment: Evidence of a gender relationship. J Opt Soc Am A Opt Image Sci Vis. 2006;23:521-538.

[36] Hammond BR, Wooten BR, Snodderly DM. Individual variations in the spatial profile of human macular pigment. J Opt Soc Am A Opt Image Sci Vis. 1997;14:1187-1196.

[37] Berendschot TTJM, van Norren D. Macular pigment shows ringlike structures. Invest Ophthalmol Vis Sci. 2006;47:709714 .

[38] Nolan JM, Stringham JM, Beatty S, et al. Spatial profile of macular pigment and its relationship to foveal architecture. Invest Ophthalmol Vis Sci. 2008;49:2134-2142.

[39] Berendschot TTJM, Goldbohm RA, Klopping WAA, et al. Influence of lutein supplementation on macular pigment, assessed with two objective techniques. Invest Ophthalmol Vis Sci. 2000;41:3322-3326.

[40] Johnson EJ, Hammond BR, Yeum KJ, et al. Relation among serum and tissue concentrations of lutein and zeaxanthin and macular pigment density. Am J Clin Nutr. 2000;71:1555-1562.

[41] Aleman TS, Duncan JL, Bieber ML, et al. Macular pigment and lutein supplementation in retinitis pigmentosa and Usher syndrome. Invest Ophthalmol Vis Sci. 2001;42:18731881.
[42] Koh HH, Murray IJ, Nolan D, et al. Serum and macular responses to lutein supplement in subjects with and without age-related maculopathy: A pilot study. Exp Eye Res. 2004;79:21-27.

[43] Schalch W, Cohn W, Barker FM, et al. Xanthophyll accumulation in the human retina during supplementation with lutein or zeaxanthin-The LUXEA (LUtein Xanthophyll Eye Accumulation) study. Arch Biochem Biophys. 2007;458:128135.

[44] Wenzel AJ, Sheehan JP, Gerweck C, et al. Macular pigment optical density at four retinal loci during 120 days of lutein supplementation. Ophthalmic Physiol Opt. 2007;27:329335.

[45] Rodriguez-Carmona M, Kvansakul J, Harlow JA, et al. The effects of supplementation with lutein and/or zeaxanthin on human macular pigment density and color vision. Ophthalmic Physiol Opt. 2006;26:137-147.

[46] Burke JD, Curran-Celentano J, Wenzel AJ. Diet and serum carotenoid concentrations affect macular pigment optical density in adults 45 years and older. J Nutr. 2005;135:12081214.

[47] Johnson EJ, Chung HY, Caldarella SM, et al. The influence of supplemental lutein and docosahexaenoic acid on serum, lipoproteins, and macular pigmentation. Am J Clin Nutr. 2008;87:1521-1529.

[48] Khachik F, de Moura FF, Chew EY, et al. The effect of lutein and zeaxanthin supplementation on metabolites of these carotenoids in the serum of persons aged 60 or older. Invest Ophthalmol Vis Sci. 2006;47:5234-5242.

[49] Curran-Celentano J, Hammond BR, Ciulla TA, et al. Relation between dietary intake, serum concentrations, and retinal concentrations of lutein and zeaxanthin in adults in a Midwest population. Am J Clin Nutr.2001;74:796-802.

[50] Richer S, Devenport J, Lang JC. LAST II: Differential temporal responses of macular pigment optical density in patients with atrophic age-related macular degeneration to dietary supplementation with xanthophylls. Optometry. 2007;78:213-219.

[51] Bone RA, Landrum JT, Guerra LH, et al. Lutein and zeaxanthin dietary supplements raise macular pigment density and serum concentrations of these carotenoids in humans. J Nutr. 2003;133:992-998.

[52] Bernstein PS, Zhao DY, Sharifzadeh M, et al. Resonance Raman measurement of macular carotenoids in the living human eye. Arch Biochem Biophys. 2004;430:163-169.

[53] Thurnham DI. Macular zeaxanthins and lutein-A review of dietary sources and bioavailability and some relationships with macular pigment optical density and age-related macular disease. Nutr Res Rev. 2007;20:163-179.

[54] Bhosale P, Larson AJ, Frederick JM, et al. Identification and characterization of a pi isoform of glutathione S-transferase (GSTP1) as a zeaxanthin-binding protein in the macula of the human eye. J Biol Chem. 2004;279:49447-49454.

[55] Bernstein PS, Khachik F, Carvalho LS, et al. Identification and quantitation of carotenoids and their metabolites in the tissues of the human eye. Exp Eye Res. 2001;72:215-223. 